\title{
Specific Stabilization of $c$-MYC and $c$-KIT G-Quadruplex DNA Structures by Indolylmethyleneindanone Scaffolds
}

\author{
K. V. Diveshkumar, ${ }^{\dagger}$ Saaz Sakrikar,${ }^{\dagger}$ Frédéric Rosu, ${ }^{\ddagger}{ }^{\S}$ S. Harikrishna,${ }^{\dagger}$ \\ Valérie Gabelica* ${ }^{*, \perp}$ and P. I. Pradeepkumar*, ${ }^{*}$ \\ ${ }^{\dagger}$ Department of Chemistry, Indian Institute of Technology Bombay, Mumbai-400076, India \\ ${ }^{\ddagger}$ CNRS, UMS3033/US001, Institut Européen de Chimie et Biologie, 33607 Pessac, \\ France \\ ${ }^{\S}$ Univ. Bordeaux, U869 ARNA Laboratory, 33600 Pessac, France \\ ${ }^{\perp}$ Inserm, U869 ARNA Laboratory, 33000 Bordeaux, France \\ E-mail: valerie.gabelica@ inserm.fr and pradeep@chem.iitb.ac.in
}

\section{TABLE OF CONTENTS}

Figure S1 CD spectra of ligands with telomeric DNA in the absence of added metal ions............Page S1

Figure S2 CD spectra of ligands with $c-M Y C$ DNA in the absence of added metal ions ..............Page S2

Figure S3 CD spectra of ligands with $c$-KIT1 DNA in the absence of added metal ions ..............Page S3

Figure S4 CD spectra of ligands with $c$-KIT2 DNA in the absence of added metal ions ..............Page S4

Figure S5 Non-denaturing gel of telomeric DNA from EMSA …................................................... S4

Figure S6 CD melting curves of $c$-KIT1, $c$-KIT2, duplex and long telomeric DNAs ....................Page S5

Figure S7 ESI-MS mass spectra of $c-K I T 1,\left(\mathrm{TG}_{4} \mathrm{~T}\right)_{4}$ and duplex DNAs with ligands...................Page S6

Figure S8 ITC profiles of ligands with telomeric quadruplex and duplex DNAs.........................Page S7

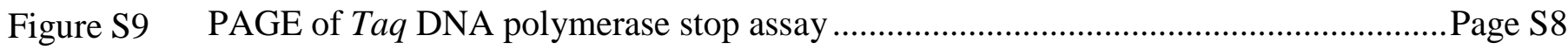

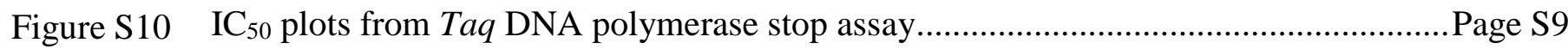

Figure S11 Energy optimized structures of ligands at HF/6-31G* level ....................................Page S10

Figure S12 Time dependent RMSD graphs of $c$-MYC DNA and InEt2 ....................................Page S10

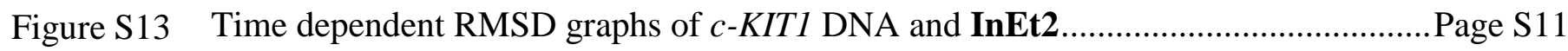

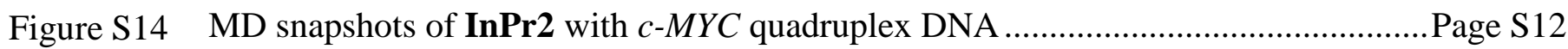

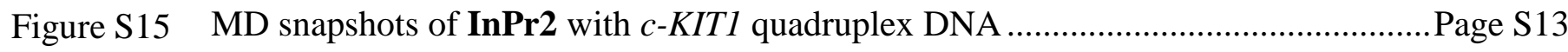

Figure S16 Time dependent RMSD graphs of telomeric antiparallel quadruplex and InEt2.........Page S14 
Figure S17 Time dependent RMSD graphs of telomeric antiparallel quadruplex and InPr2 Page S15

Figure S18 Time dependent RMSD graphs of telomeric hybrid quadruplex and InEt2 Page S16

Figure S19 Time dependent RMSD graphs of telomeric hybrid quadruplex and InPr2 Page S17

Figure S20 Time dependent RMSD graphs of telomeric parallel quadruplex and InEt2. Page S18

Figure S21 Time dependent RMSD graphs of telomeric parallel quadruplex and InPr2 Page S19

Figure S22 MD snapshots of InEt2 and InPr2 with telomeric parallel quadruplex DNA. Page S20

Figure S23 MD snapshots of InEt2 and InPr2 with telomeric antiparallel quadruplex DNA.......Page S21

Figure S24 MD snapshots of InEt2 and InPr2 with telomeric hybrid quadruplex DNA Page S22

Table S1 Oligonucleotides used for biophysical and biochemical studies Page S23

Table S2 Thermodynamic parameters of telomeric quadruplex and duplex DNAs from ITC....Page S23

Table S3 Average RMSDs of G-quadruplex DNAs and InEt2 complex Page S24

Table S4 Hoogsteen H-bond occupancies in G-quartet during MD simulations of InEt2..........Page S24

Table S5 Binding free energy components of InEt2-c-MYC quadruplex DNA complex ...........Page S25

Table S6 Binding free energy components of InEt2-c-KIT1 quadruplex DNA complex Page S26

Table S7 Binding free energy components of InEt2-telomeric G-quadruplex DNA complexesPage S27

Table S8 Binding free energy components of InPr2-telomeric G-quadruplex DNA complexesPage S28 Percentage lifetime occupancies of stacking interactions over $100 \mathrm{~ns}$ of MD simulations

Table S9

Page S28

${ }^{1} \mathrm{H}$ NMR $\&{ }^{13} \mathrm{C}$ NMR spectrum of compound 2 Page S29

${ }^{1} \mathrm{H}$ NMR \& ${ }^{13} \mathrm{C}$ NMR spectrum of compound 3 . Page S30

${ }^{1} \mathrm{H}$ NMR \& ${ }^{13} \mathrm{C}$ NMR spectrum of compound 4 Page S31

${ }^{1} \mathrm{H}$ NMR \& ${ }^{13} \mathrm{C}$ NMR spectrum of compound 5 Page S32

${ }^{1} \mathrm{H}$ NMR \& ${ }^{13} \mathrm{C}$ NMR spectrum of compound InEt1 Page S33

${ }^{1} \mathrm{H}$ NMR \& ${ }^{13} \mathrm{C}$ NMR spectrum of compound InPr1 Page S34

${ }^{1} \mathrm{H}$ NMR \& ${ }^{13} \mathrm{C}$ NMR spectrum of compound $\mathbf{1 0}$ Page S35

${ }^{1} \mathrm{H}$ NMR \& ${ }^{13} \mathrm{C}$ NMR spectrum of compound $\mathbf{1 1}$ Page S36

${ }^{1} \mathrm{H}$ NMR \& ${ }^{13} \mathrm{C}$ NMR spectrum of compound $\mathbf{1 2}$ Page S37

${ }^{1} \mathrm{H}$ NMR \& ${ }^{13} \mathrm{C}$ NMR spectrum of compound 13 Page S38

${ }^{1} \mathrm{H}$ NMR \& ${ }^{13} \mathrm{C}$ NMR spectrum of compound InEt2 Page S39

${ }^{1} \mathrm{H}$ NMR \& ${ }^{13} \mathrm{C}$ NMR spectrum of compound InPr2 Page S40 


\section{CD spectra of ligands with telomeric DNA in the absence of added metal ions}
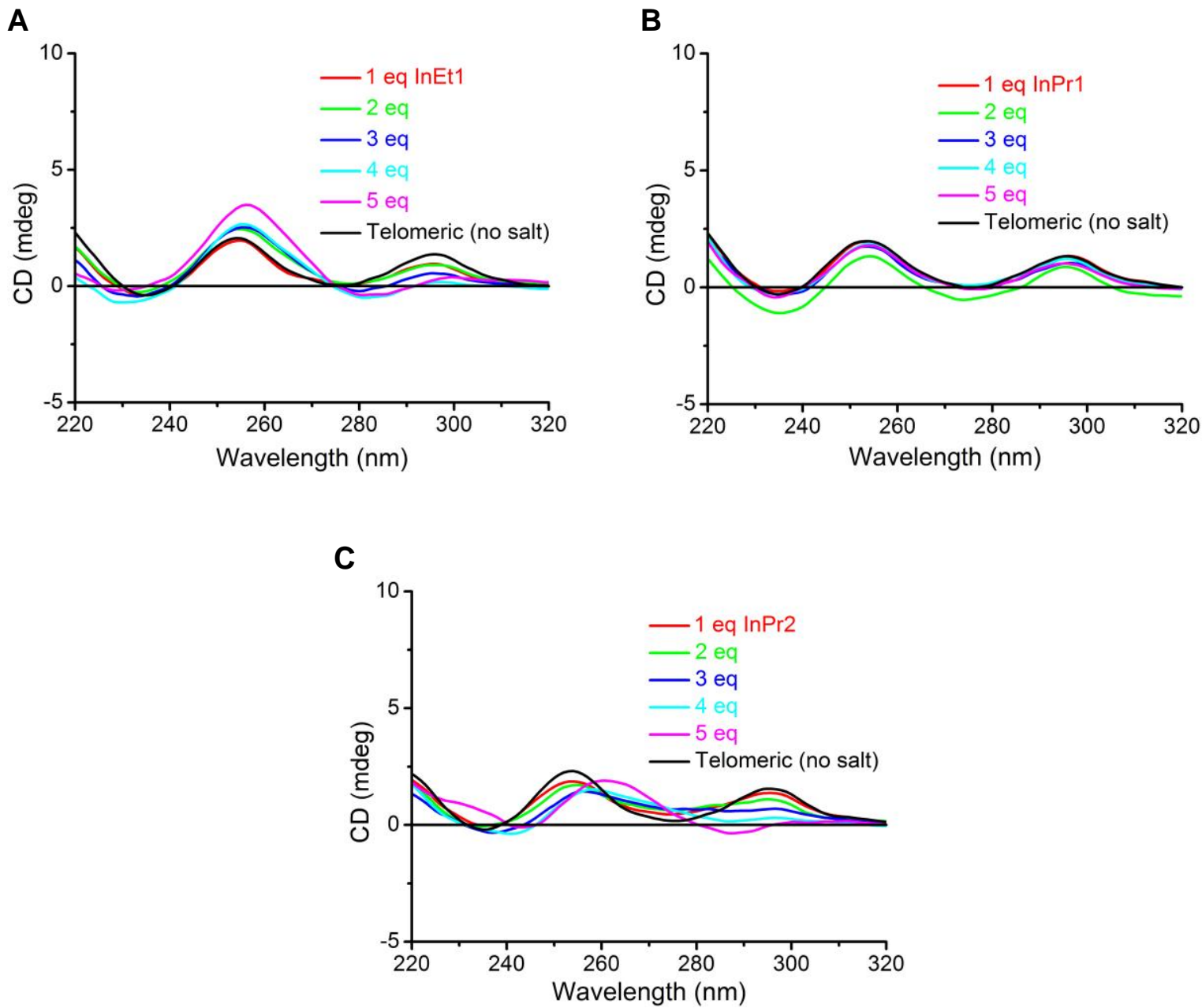

Figure S1. CD titration spectra of ligands with telomeric DNA $(12.5 \mu \mathrm{M}$ DNA in $50 \mathrm{mM}$ Tris- $\mathrm{HCl}$, pH 7.2) in the absence of added metal ions. (A) InEt1; (B) InPr1; and (C) InPr2. 


\section{CD spectra of ligands with $c-M Y C$ DNA in the absence of added metal ions}

A

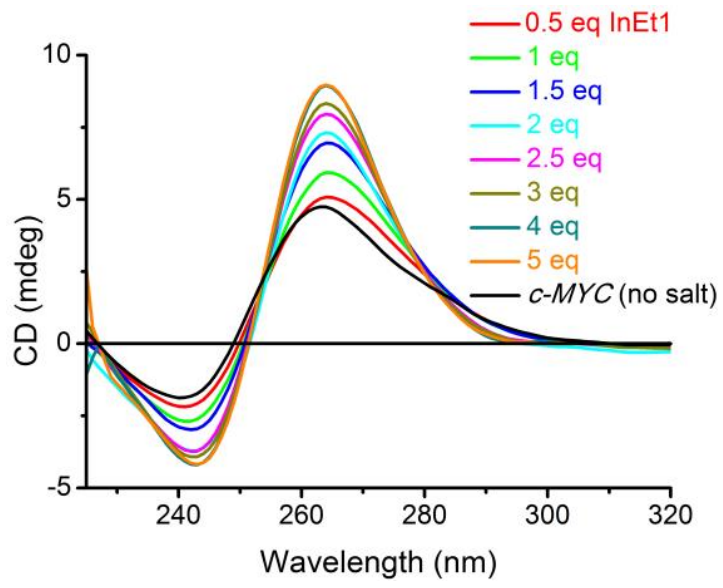

B

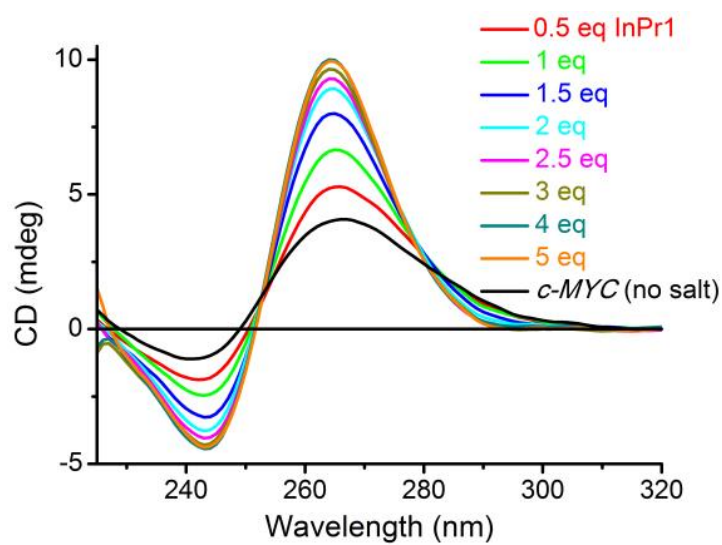

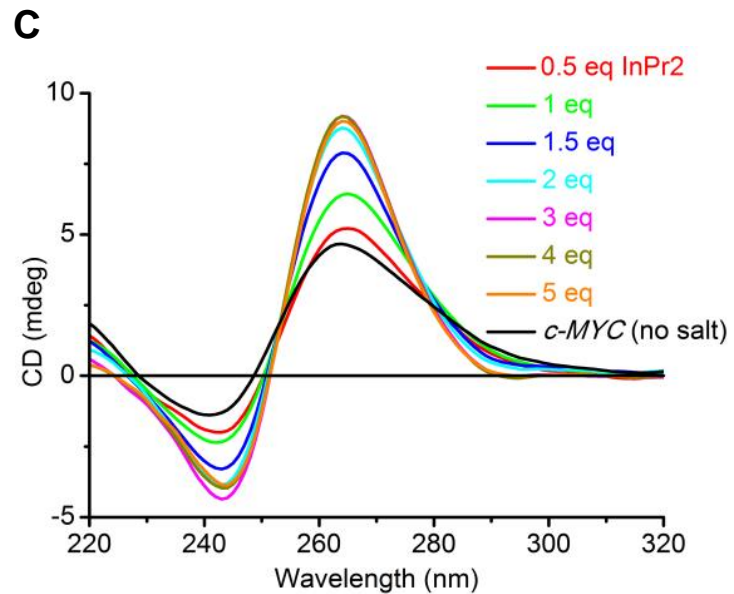

Figure S2. CD titration spectra for ligands with $c-M Y C$ DNA $(12.5 \mu \mathrm{M}$ DNA in $50 \mathrm{mM}$ Tris-HCl, pH 7.2) in the absence of added metal ions. (A) InEt1; (B) InPr1; and (C) InPr2. 


\section{CD spectra of ligands with $c$-KIT1 DNA in the absence of added metal ions}

A

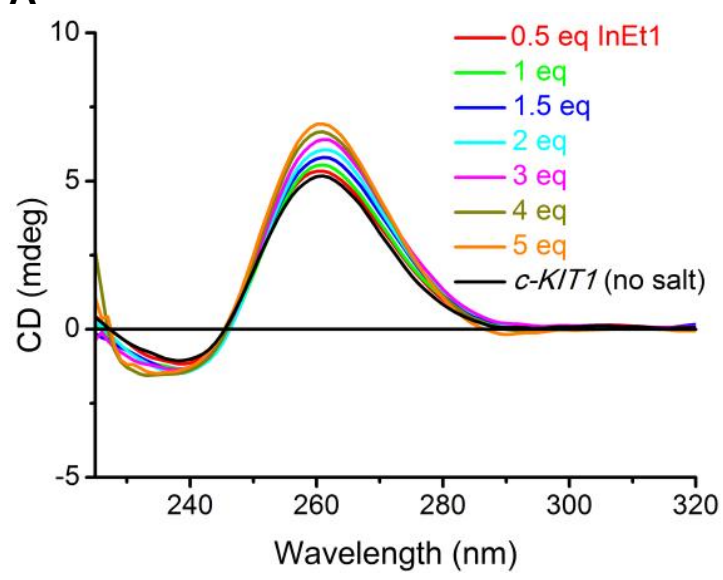

C

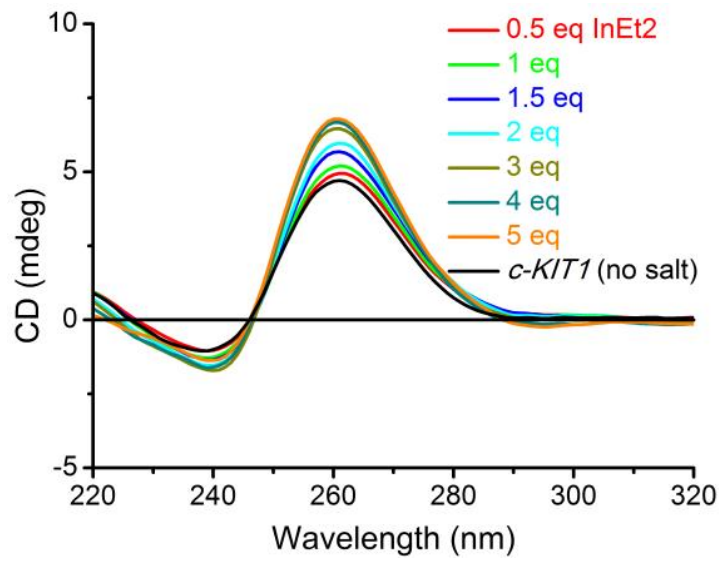

B

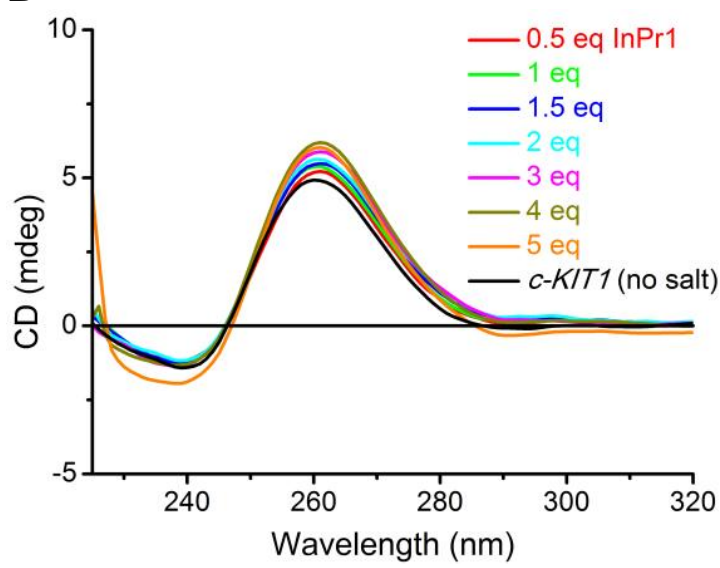

D

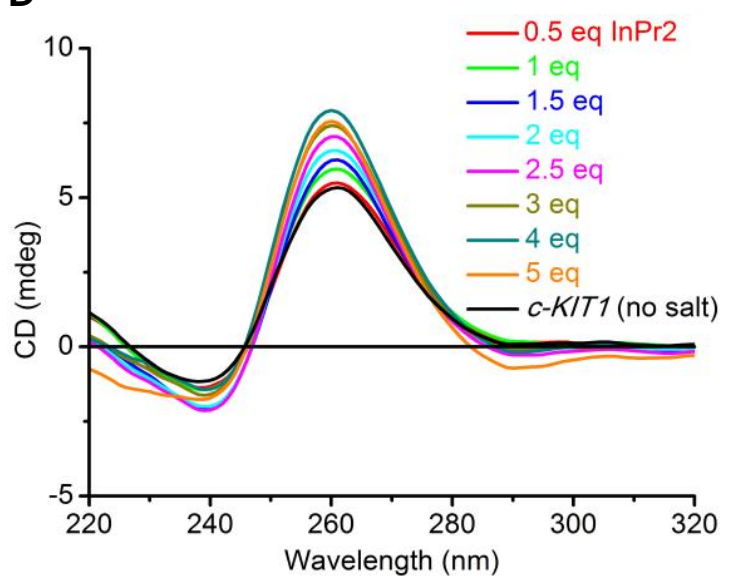

Figure S3. CD titration spectra of ligands with $c-$ KITl DNA $(12.5 \mu \mathrm{M}$ DNA in $50 \mathrm{mM}$ Tris-HCl, $\mathrm{pH}$ 7.2) in the absence of added metal ions. (A) InEt1; (B) InPr1; (C) InEt2; and (D) InPr2. 


\section{CD spectra of ligands with $c$-KIT2 DNA in the absence of added metal ions}
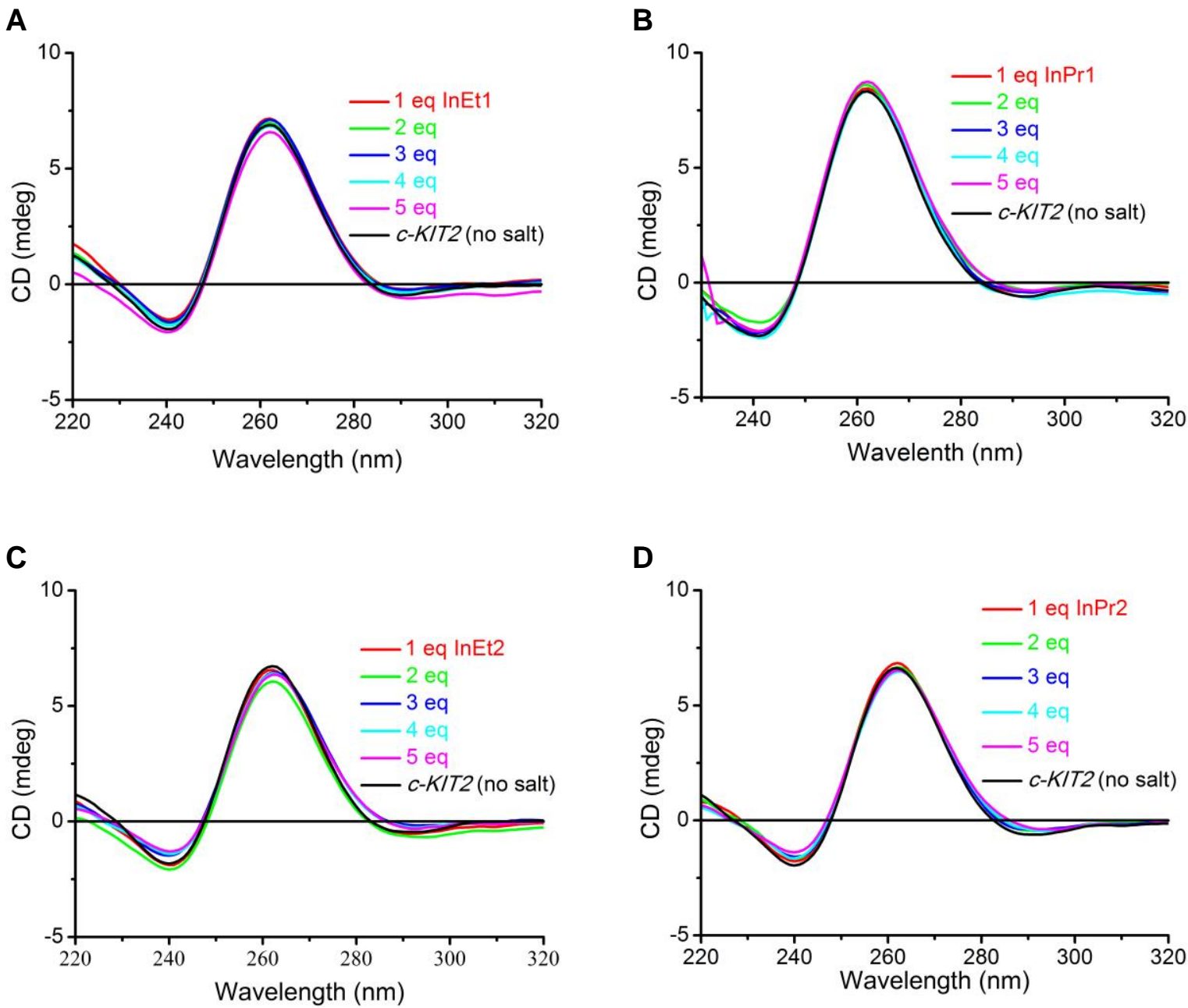

Figure S4. CD titration spectra of ligands with $c-K I T 2$ DNA $(12.5 \mu \mathrm{M}$ DNA in $50 \mathrm{mM}$ Tris- $\mathrm{HCl}, \mathrm{pH}$ 7.2) in the absence of added metal ions. (A) InEt1; (B) InPr1; (C) InEt2; and (D) InPr2.

\section{Nondenaturing gel of telomeric DNA from EMSA}

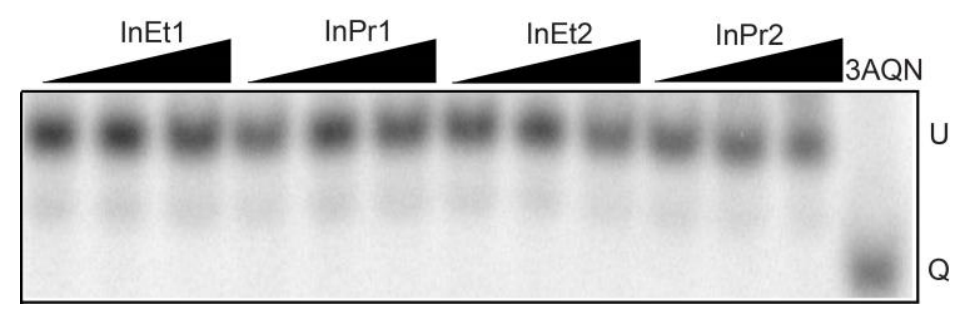

Figure S5. Nondenaturing PAGE of telomeric DNA (5 $\mu \mathrm{M}$ in $10 \mathrm{mM}$ Tris- $\mathrm{HCl}, \mathrm{pH}$ 7.2) with increasing molar equivalents of ligands $(0,5$ and 10$)$ in the absence of added monovalent cations at 22 ${ }^{\circ} \mathrm{C}$. Induction of stable compact quadruplex structure by the control ligand 3AQN (5 equivalents) resulted in accelerated mobility of telomeric DNA and no acceleration observed for the telomeric DNA bands after titration with the ligands. $\mathbf{U}$ denotes non-quadruplex forms and $\mathbf{Q}$ denotes quadruplex forms. 


\section{CD melting curves of $c$-KIT1, $c$-KIT2 quadruplex, duplex and long telomeric DNAs}

A

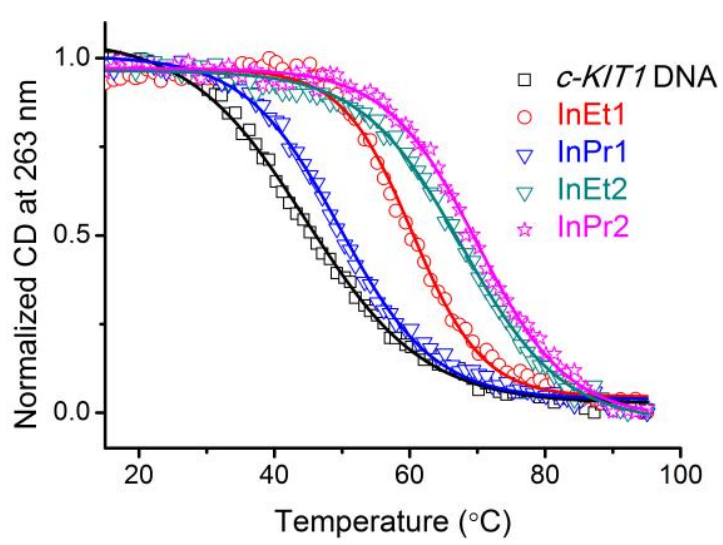

C

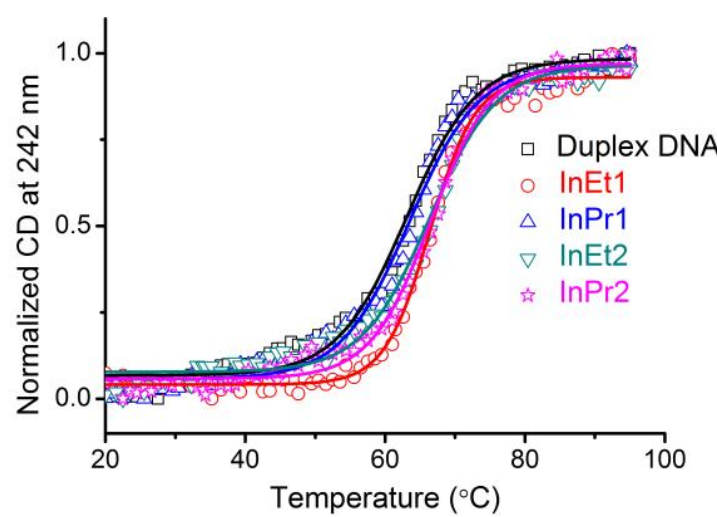

B

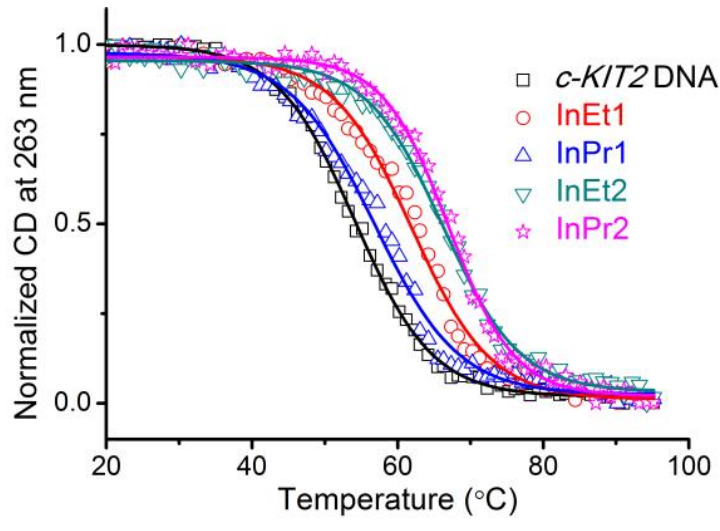

D

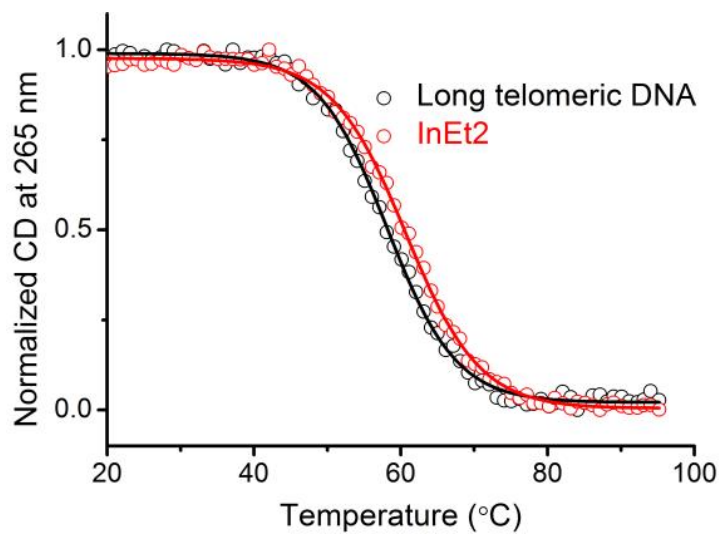

Figure S6. CD melting curves of $c$-KIT, duplex and long telomeric DNAs $(10 \mathrm{mM}$ lithium cacodylate buffer, $\mathrm{pH}$ 7.2) in the absence and presence of 5 equivalents of ligands. (A) $c$-KIT1 (10 $\mu \mathrm{M}$ in $10 \mathrm{mM}$ $\mathrm{KCl}$ and $90 \mathrm{mM} \mathrm{LiCl}$ ); (B) $c$-KIT2 DNA (10 $\mu \mathrm{M}$ in $1 \mathrm{mM} \mathrm{KCl,} 99 \mathrm{mM} \mathrm{LiCl})$; (C) Duplex DNA (15 $\mu \mathrm{M}$ in $10 \mathrm{mM} \mathrm{KCl}$ and $90 \mathrm{mM} \mathrm{LiCl})$; and (D) Long telomeric DNA $(10 \mu \mathrm{M}$ in $100 \mathrm{mM} \mathrm{KCl})$ 


\section{ESI-MS mass spectra of $c$-KIT1, (TG4 $\mathrm{T}_{4}$ and duplex DNAs with ligands}
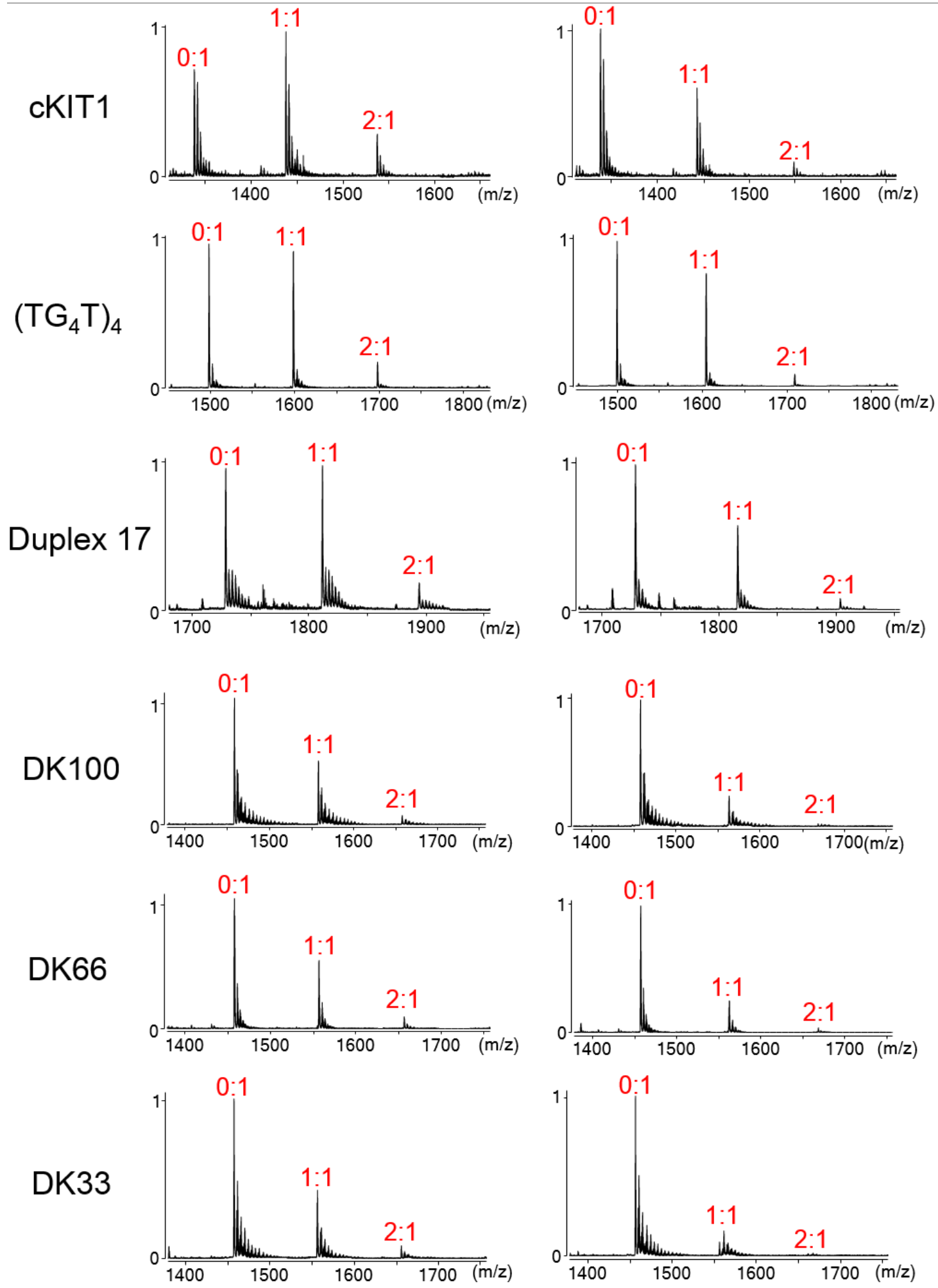

Figure S7. ESI-MS spectra with zoom on the 5- charge state of $c-K I T 1$, $\left(\mathrm{TG}_{4} \mathrm{~T}\right)_{4}$, telomeric quadruplex and duplex DNAs of different GC content $(5 \mu \mathrm{M}$ DNA, $10 \mu \mathrm{M}$ ligands in $100 \mathrm{mM}$ $\mathrm{NH}_{4} \mathrm{OAc}$ solution) at $22{ }^{\circ} \mathrm{C}$. Left column: InEt2 ligand. Right column: InPr2 ligand. Peak annotations indicate the stoichiometry as (number of ligands bound):(target structure). 


\section{ITC profiles of ligands with quadruplex and duplex DNAs}

A

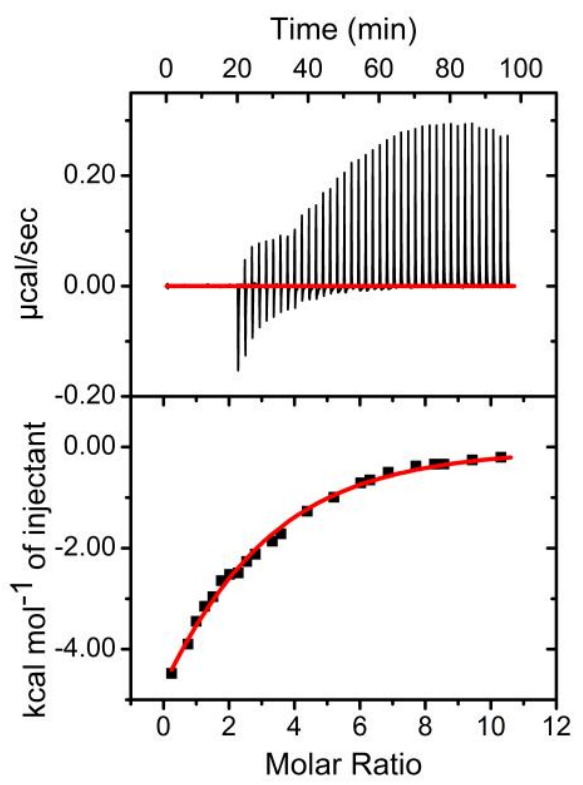

C

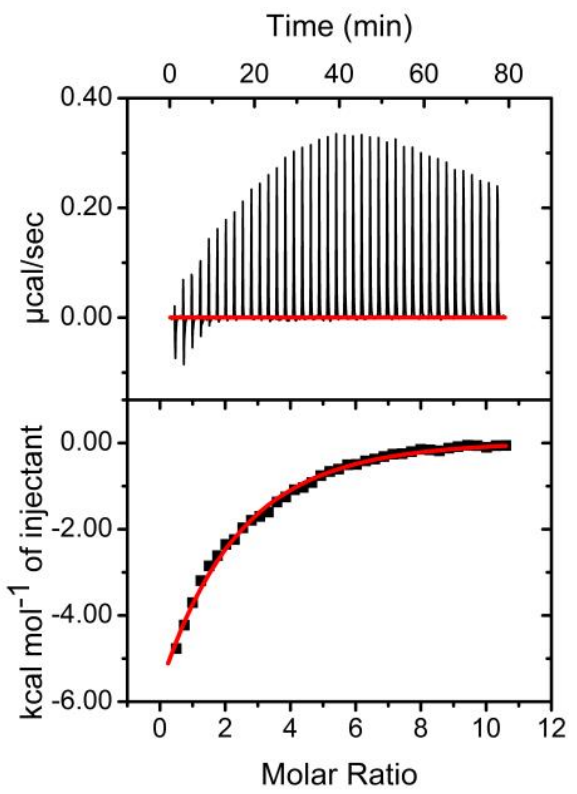

B

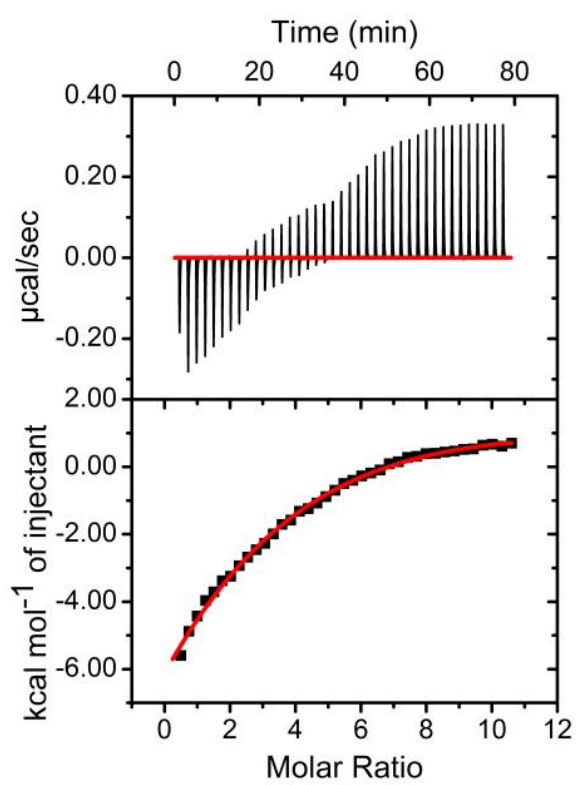

D

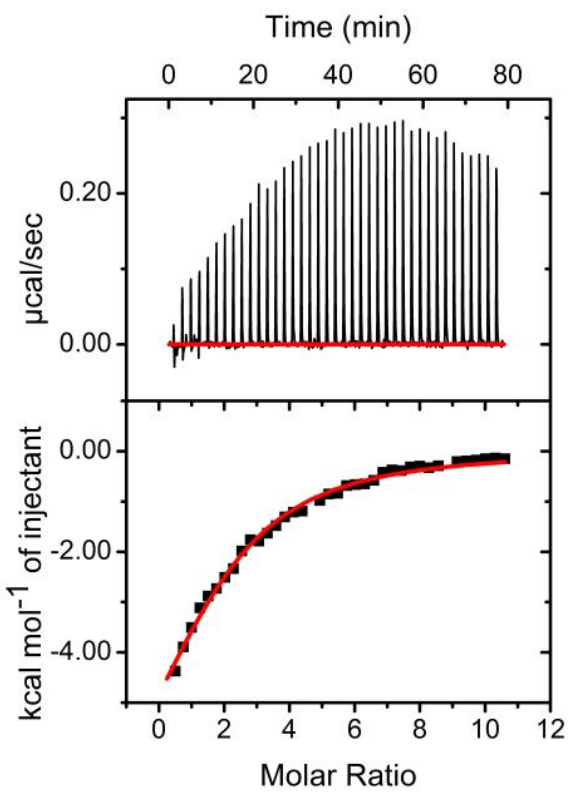

Figure S8. ITC profiles for the interaction of ligand InEt2 and InPr2 with quadruplex and duplex DNAs $(50 \mu \mathrm{M}$ DNA in $100 \mathrm{mM} \mathrm{KCl}$ and $10 \mathrm{mM}$ lithium cacodylate buffer, $\mathrm{pH}$ 7.2). (A) Telomeric DNA with InEt2; (B) Duplex DNA with InEt2; (C) Telomeric DNA with InPr2; and (D) Duplex DNA with InPr2. Raw data shown in upper panel and curve fit by using sequential binding mode after subtracting the heats of dilution is shown in the bottom panel. 


\section{PAGE of Taq DNA polymerase stop assay}

A

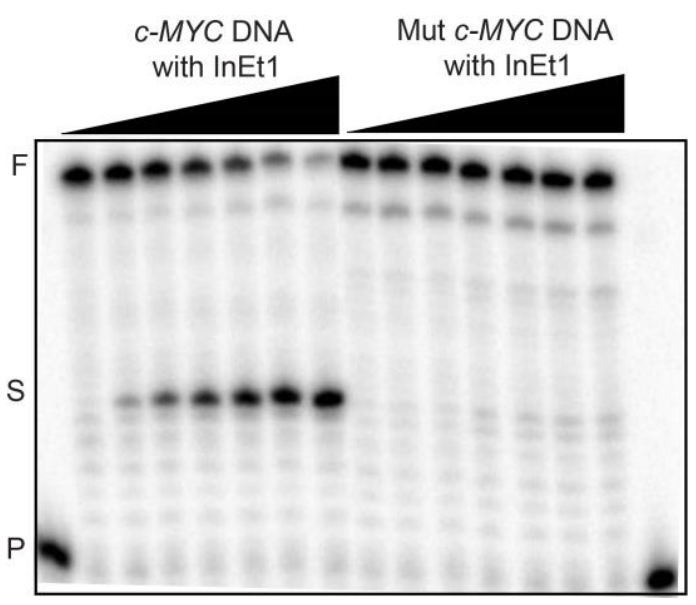

C
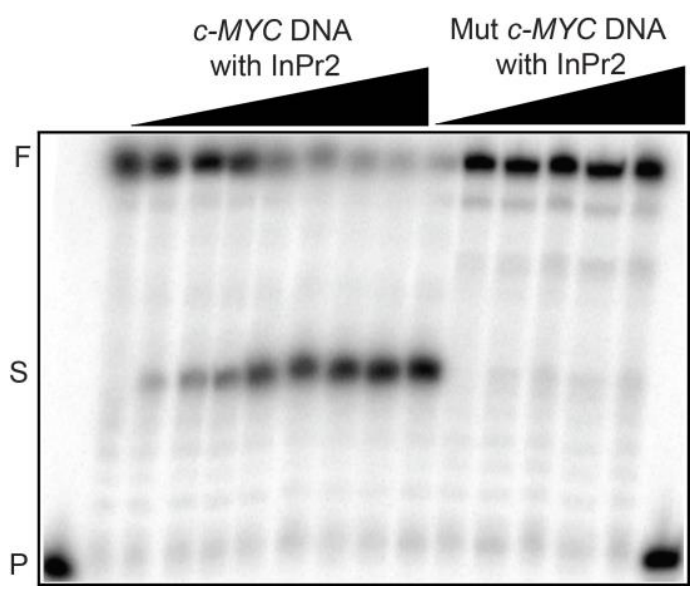

B

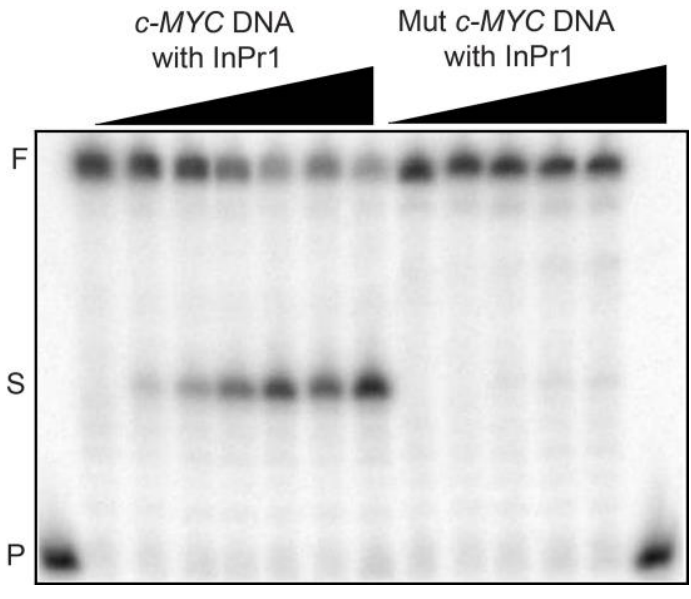

D

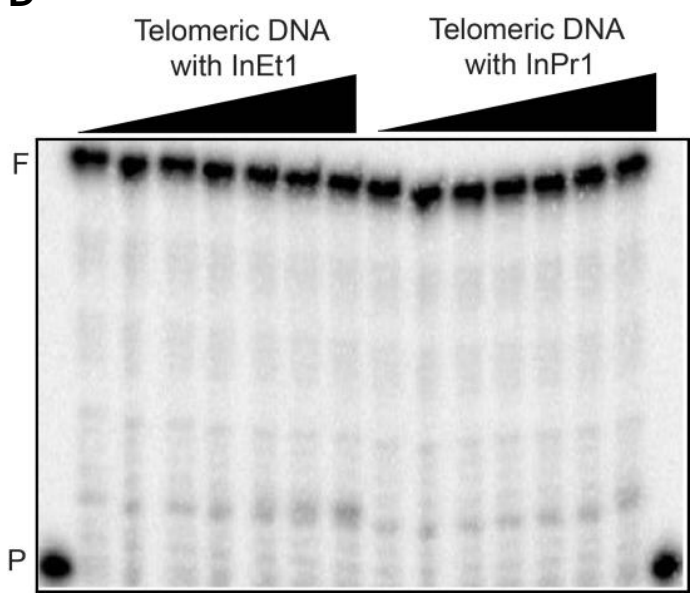

Figure S9. Denaturing PAGE (15\%, 7M urea) of Taq DNA polymerase stop assay of ligands with $c$ MYC (A-C) and telomeric quadruplex (D) DNAs. (A) InEt1 (0-80 $\mu \mathrm{M})$; (B) InPr1 (0-160 $\mu \mathrm{M})$; (C) InPr2 $(0-10 \mu \mathrm{M})$; and (D) InEt1 and InPr1 (0-120 $\mu \mathrm{M})$. Primer extension reactions were carried out at $50{ }^{\circ} \mathrm{C}$ for $c-M Y C$ DNA and at $40{ }^{\circ} \mathrm{C}$ for telomeric DNA. Conditions: $100 \mathrm{nM}$ template, $50 \mathrm{nM}$ primer, $0.2 \mathrm{mM}$ dNTPs in Taq polymerase buffer (50 mM Tris, $0.5 \mathrm{mM}$ DTT, $0.1 \mathrm{mM}$ EDTA, $5 \mathrm{mM}$ $\mathrm{MgCl}_{2}, 5 \mathrm{mM} \mathrm{KCl}$ for $c-M Y C$ template and $10 \mathrm{mM} \mathrm{KCl}$ for telomeric template). 


\section{$\underline{\text { IC } 50 \text { plots from Taq DNA polymerase stop assay }}$}

A

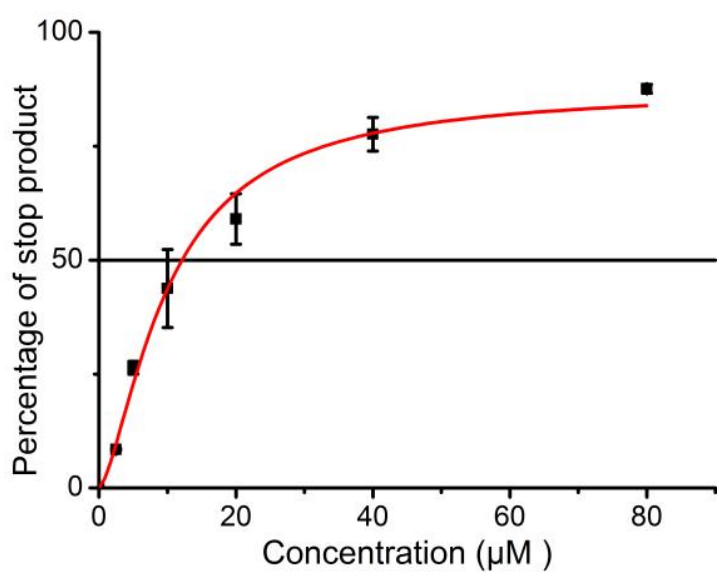

C

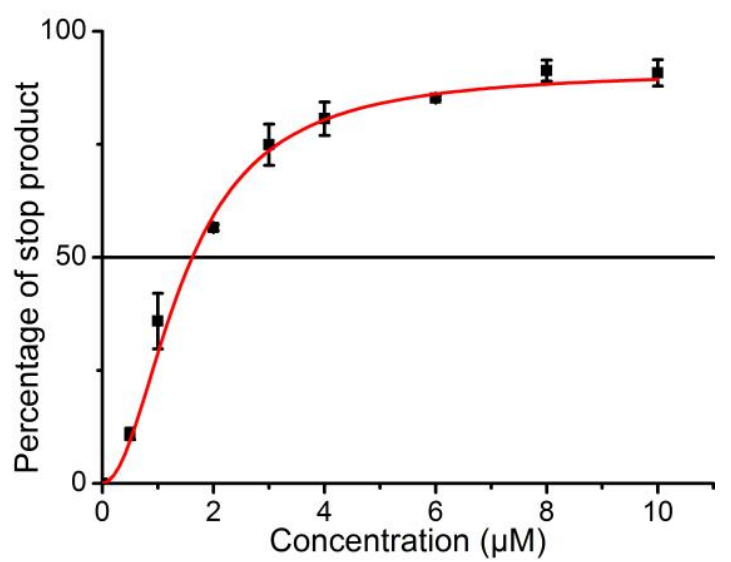

B

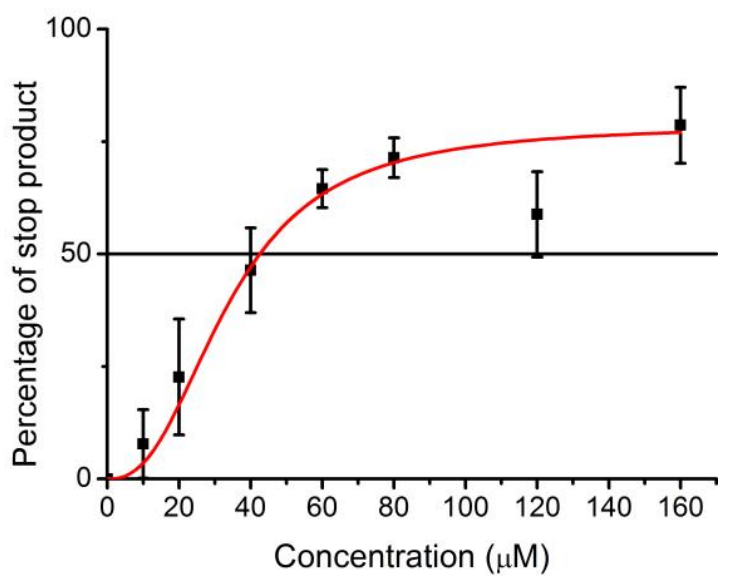

D

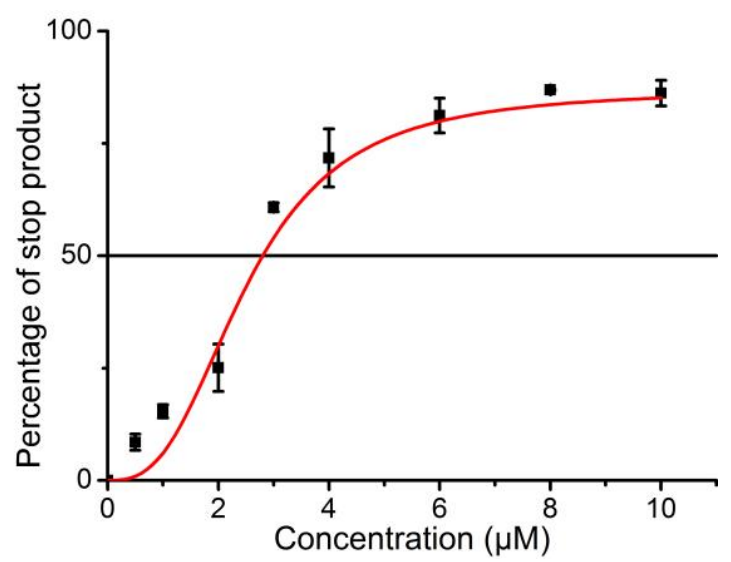

Figure S10. Plots of Taq DNA polymerase stop products versus ligand concentration. Normalized percentage of stop products in each lane was plotted against concentration of ligand. (A) InEt1 (0-80 $\mu \mathrm{M})$; (B) InPr1 (0-160 $\mu \mathrm{M})$; (C) InEt2 $(0-10 \mu \mathrm{M})$; and (D) InPr2 $(0-10 \mu \mathrm{M})$. Error bar represents standard deviation from 3 independent experiments. 


\section{Energy optimized structures of ligands at HF/6-31G* level}
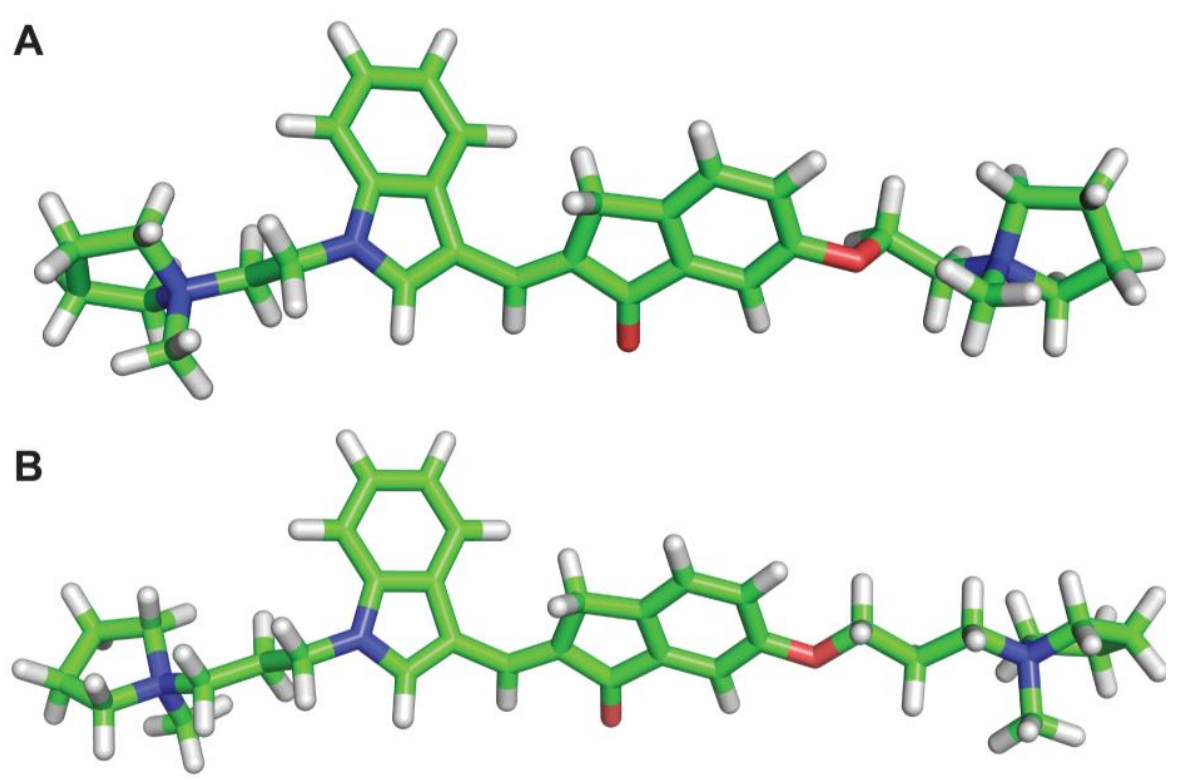

Figure S11. Energy optimized structures of (A) InEt2; and (B) InPr2 using HF/6-31G* level in Gaussian 09. RESP charges were calculated at same level in Gaussian 09. Figures were rendered using PyMOL.

\section{Time dependent RMSD graphs of $c-M Y C$ DNA and InEt2}
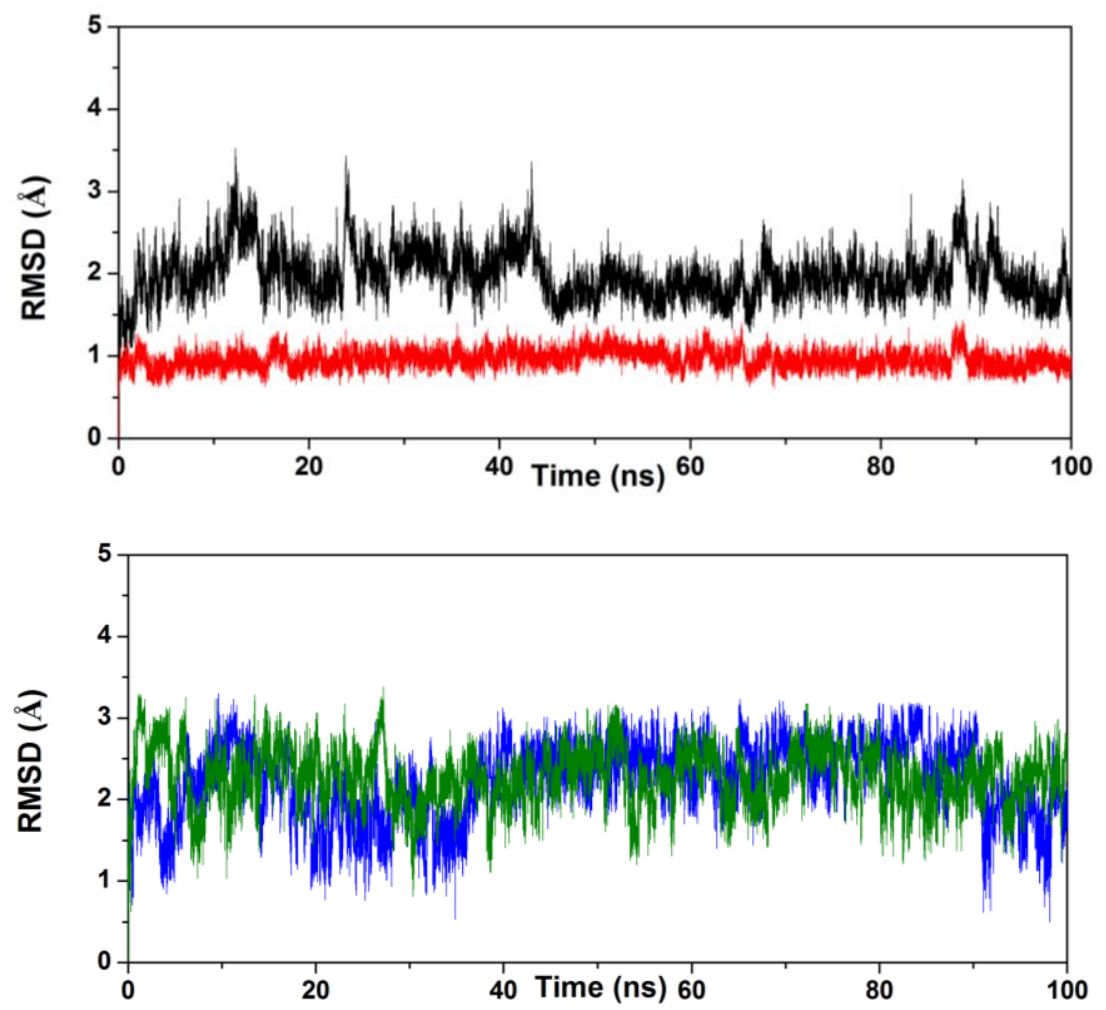

Figure S12. Time dependent root mean square deviation graphs (RMSD) of $c-M Y C$ G-quadruplex DNA complexed with InEt2. RMSD of backbone (black), G-quartet (red), 5'-InEt2 (blue) and 3'InEt2 (green) were plotted against time. RMSDs were calculated at each ps during $100 \mathrm{~ns}$ of MD simulations using ptraj module in AMBER 14. 


\section{Time dependent RMSD graphs of $c$-KIT1 DNA and InEt2}
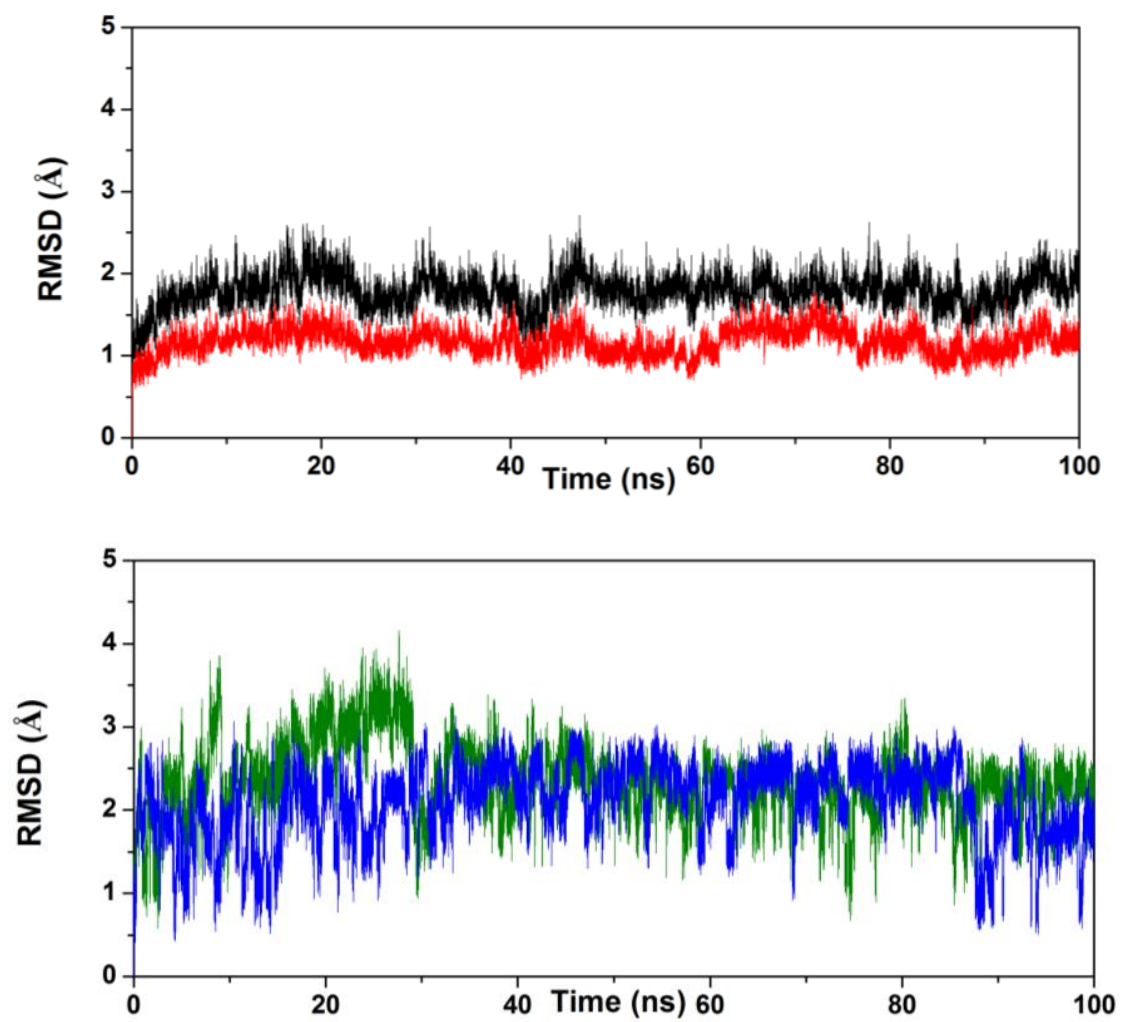

Figure S13. Time dependent root mean square deviation graphs (RMSD) of $c$-KIT1 G-quadruplex DNA complexed with InEt2. RMSD of backbone (black), G-quartet (red), 5'-InEt2 (blue) and 3'InEt2 (green) were plotted against time. RMSDs were calculated at each ps during $100 \mathrm{~ns}$ of MD simulations using ptraj module in AMBER 14. 


\section{MD snapshots of InPr2 with $c-M Y C$ quadruplex DNA}
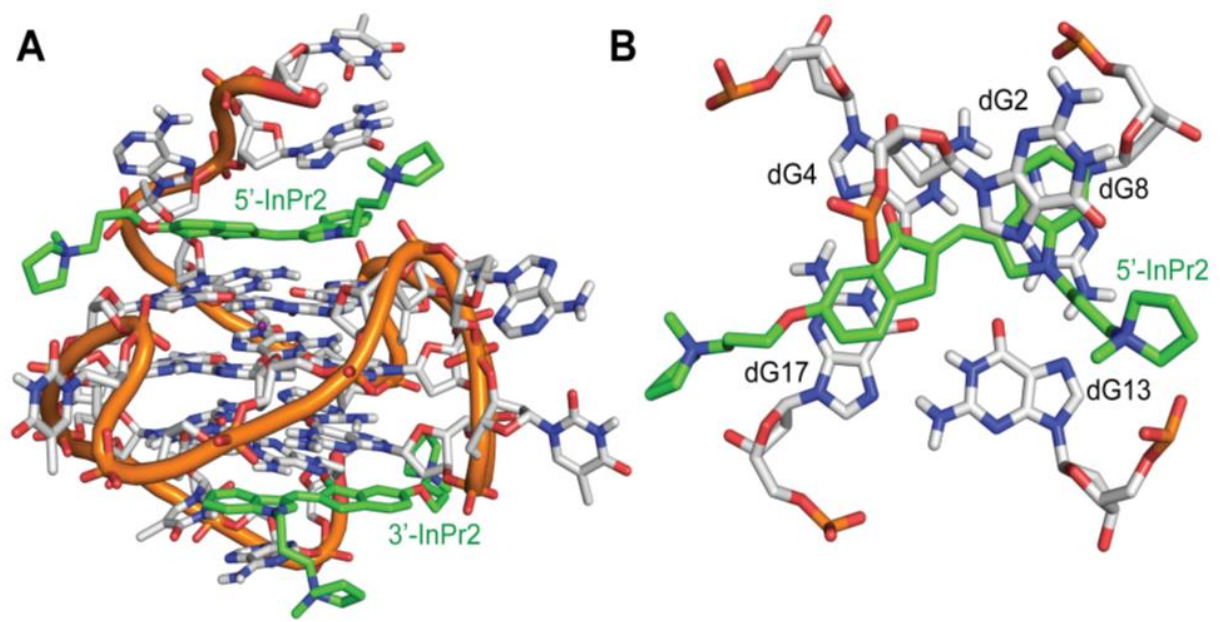

C

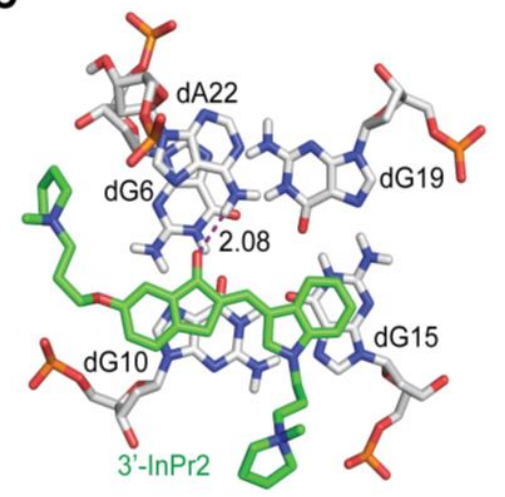

D

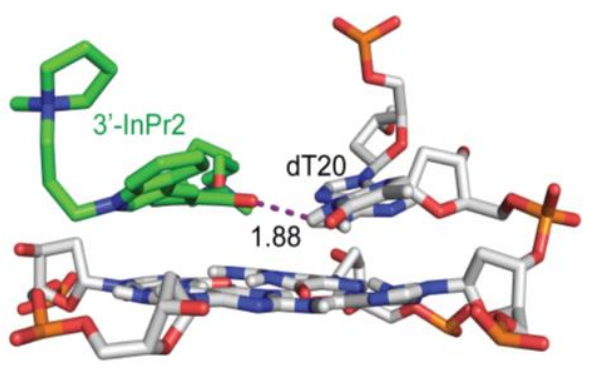

Figure S14. MD snapshots of InPr2 with $c$-MYC G-quadruplex DNA at 100 ns of the MD simulation. (A) InPr2 and $c$-MYC G-quadruplex DNA (2:1): stacking occurs at both the 5' and 3' Gquartets of the G-quadruplex DNA; (B) InPr2 and 5' quartet, showing stacking with $5^{\prime}$ quartet guanines as well as flanking nucleotide; (C) InPr2 and 3' quartet, showing the hydrogen bonding with the flanking nucleotide (dA22) and stacking with 3' quartet residues; and (D) Snapshot of 3'-InPr2 at $60 \mathrm{~ns}$, where the ligand has moved into a position where the H-bond is with dT20 and stacking of indole ring with the quartet is disrupted. This position is seen for $34 \%$ of the MD run. Dashed lines indicate the hydrogen bond distance between the atoms in ligand and G-quadruplex DNA while red lines indicate stacking distances; all distances are given in $\AA$. 


\section{MD snapshots of InPr2 with $c$-KIT1 quadruplex DNA}
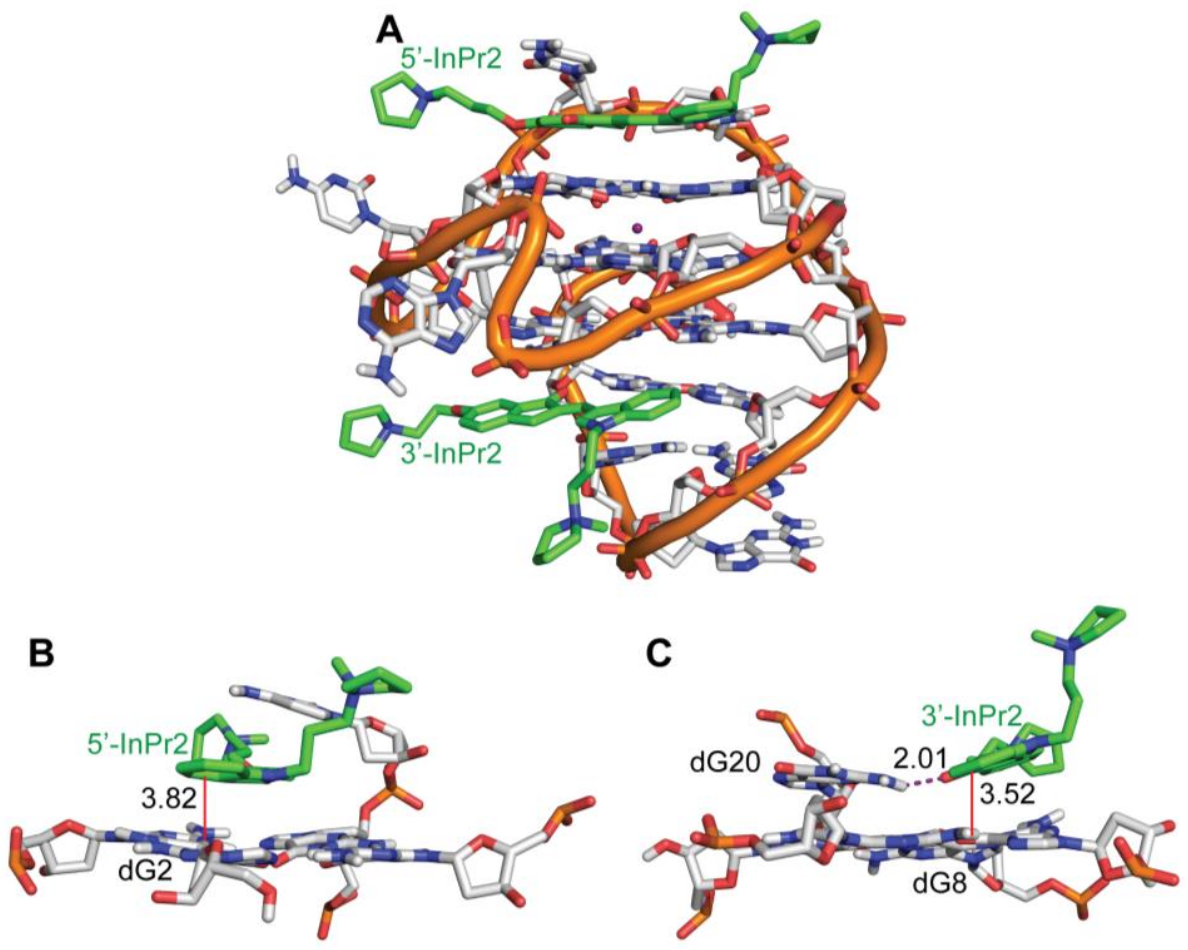

Figure S15. MD snapshots of InPr2 with $c$-KIT1 G-quadruplex DNA at $100 \mathrm{~ns}$ of the MD simulation. (A) InPr2 and $c$-KIT1 G-quadruplex DNA (2:1): stacking occurs at both the 5' and 3' G-quartets of the G-quadruplex; (B) InPr2 and 5' quartet, showing stacking from indanone and indole rings to 5' quartet residues dG10 and dG2 respectively; and (C) InPr2 and 3' quartet, showing stacking with 3' quartet guanines and H-bonding with flanking dG20. Dashed lines indicate the hydrogen bond distance between the atoms in ligand and G-quadruplex DNA, while red lines indicate stacking distances; all the distances are given in $\AA$. 


\section{Time dependent RMSD graphs of telomeric antiparallel quadruplex and InEt2}
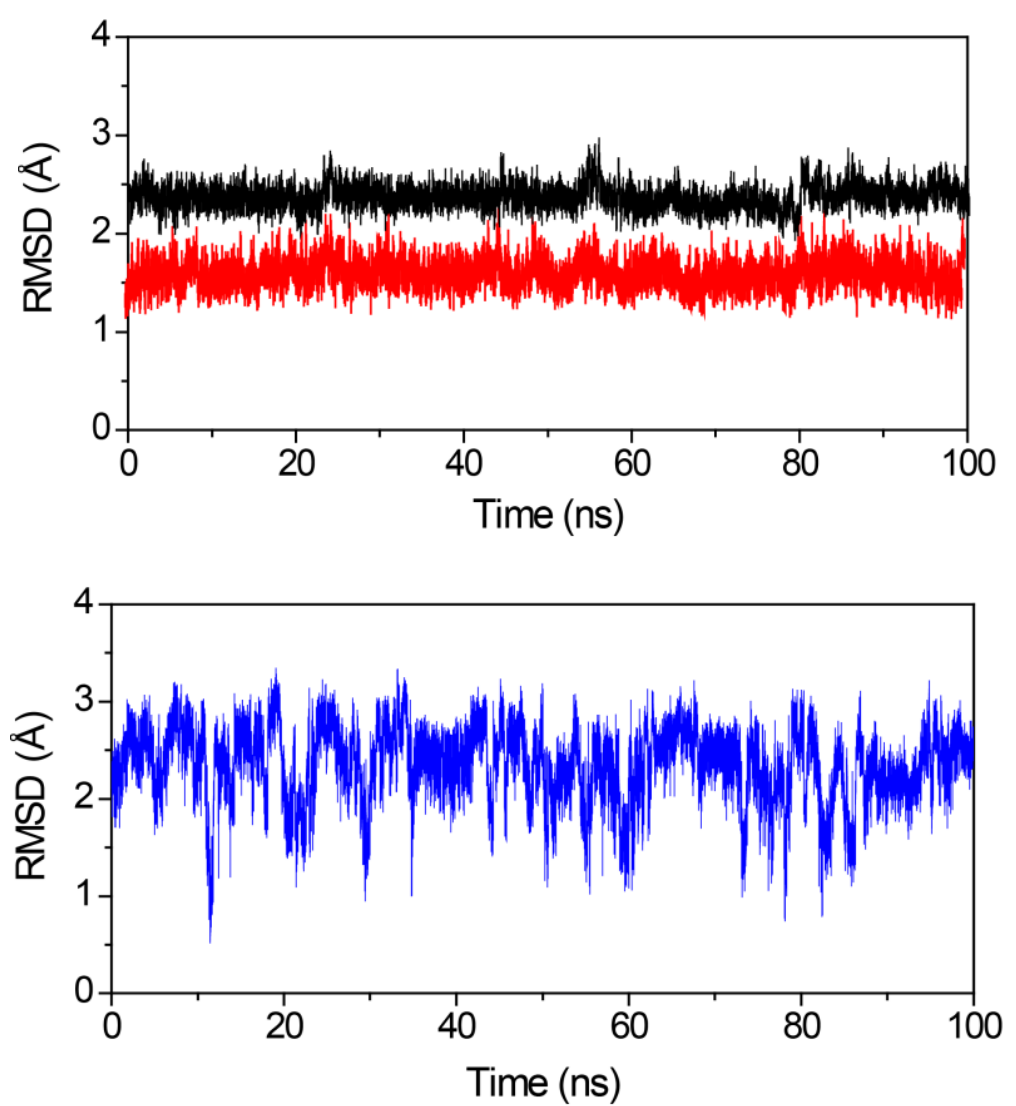

Figure S16. Time dependent root mean square deviation graphs (RMSD) of telomeric antiparallel Gquadruplex DNA complexed with InEt2. RMSD of backbone (black), G-quartet (red), InEt2 (blue) were plotted against time. RMSDs were calculated at each ps during the $100 \mathrm{~ns}$ of MD simulations using ptraj module in AMBER 14. 


\section{Time dependent RMSD graphs of telomeric antiparallel quadruplex and InPr2}
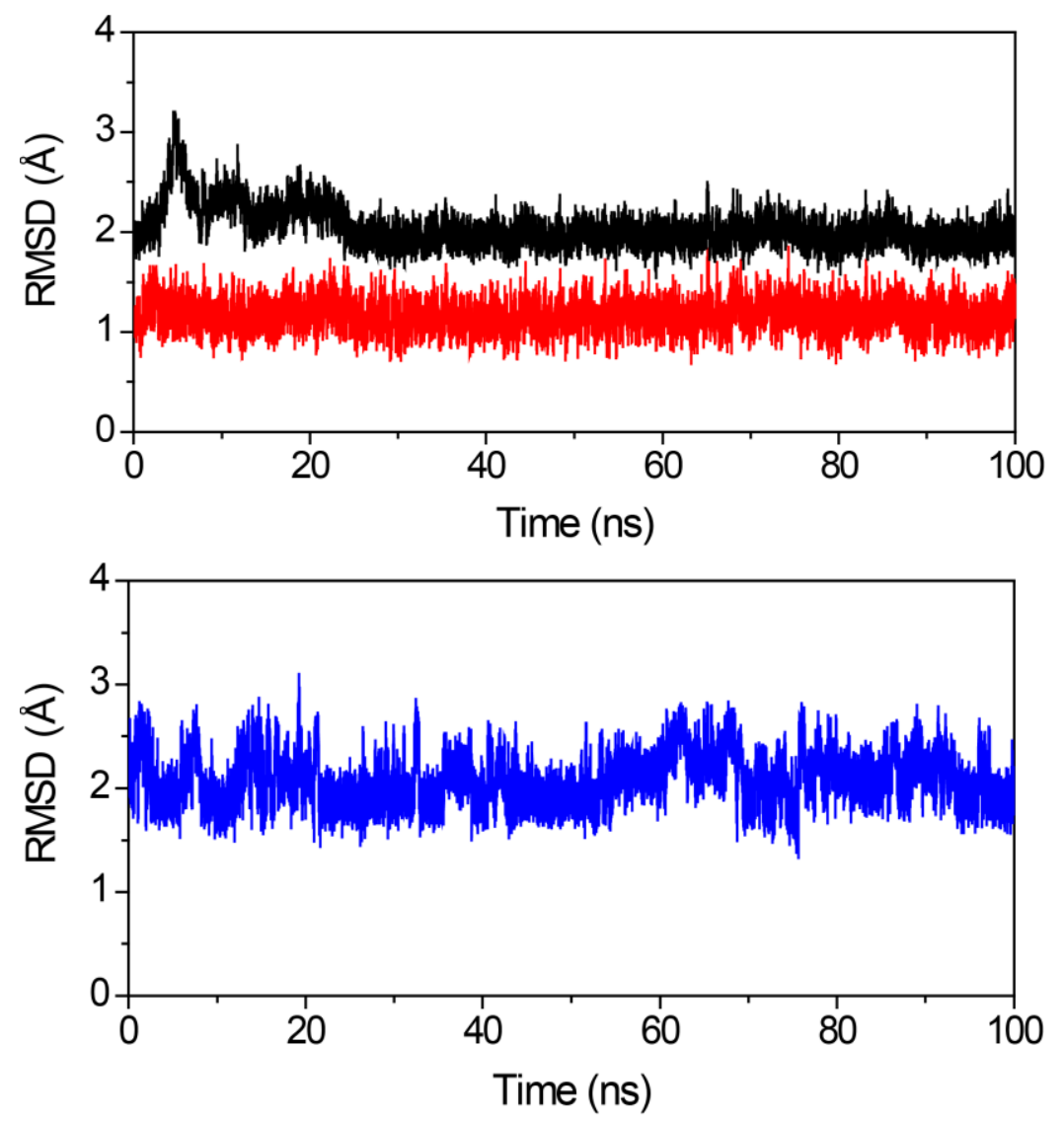

Figure S17. Time dependent root mean square deviation graphs (RMSD) of telomeric antiparallel Gquadruplex DNA complexed with InPr2. RMSD of backbone (black), G-quartet (red), InPr2 (blue) were plotted against time. RMSDs were calculated at each ps during the $100 \mathrm{~ns}$ of MD simulations using ptraj module in AMBER 14. 


\section{Time dependent RMSD graphs of telomeric hybrid quadruplex and InEt2}
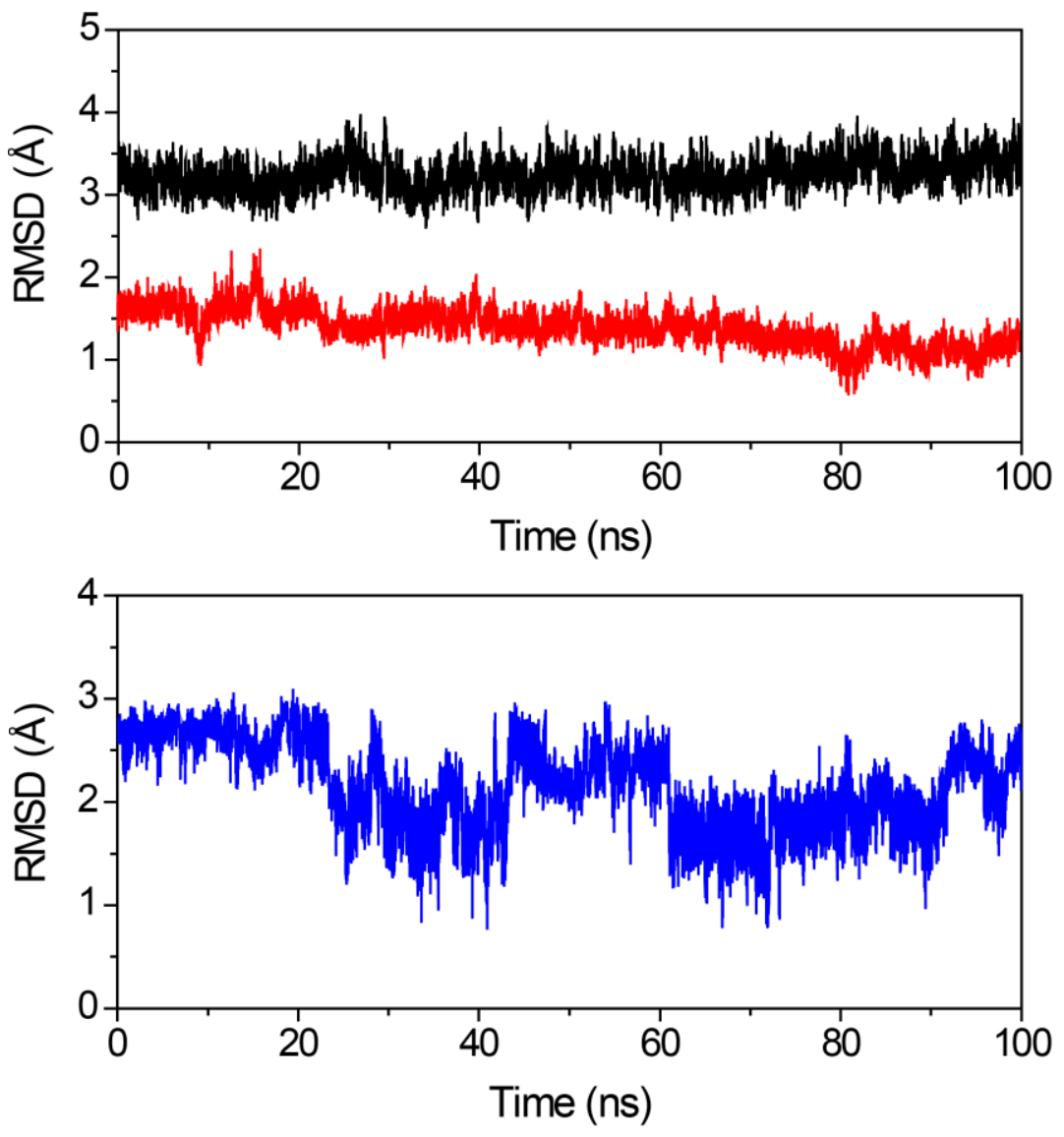

Figure S18. Time dependent root mean square deviation graphs (RMSD) of telomeric hybrid Gquadruplex DNA complexed with InEt2. RMSD of backbone (black), G-quartet (red), InEt2 (blue) were plotted against time. RMSDs were calculated at each ps during the $100 \mathrm{~ns}$ of MD simulations using ptraj module in AMBER 14. 


\section{Time dependent RMSD graphs of telomeric hybrid quadruplex and InPr2}
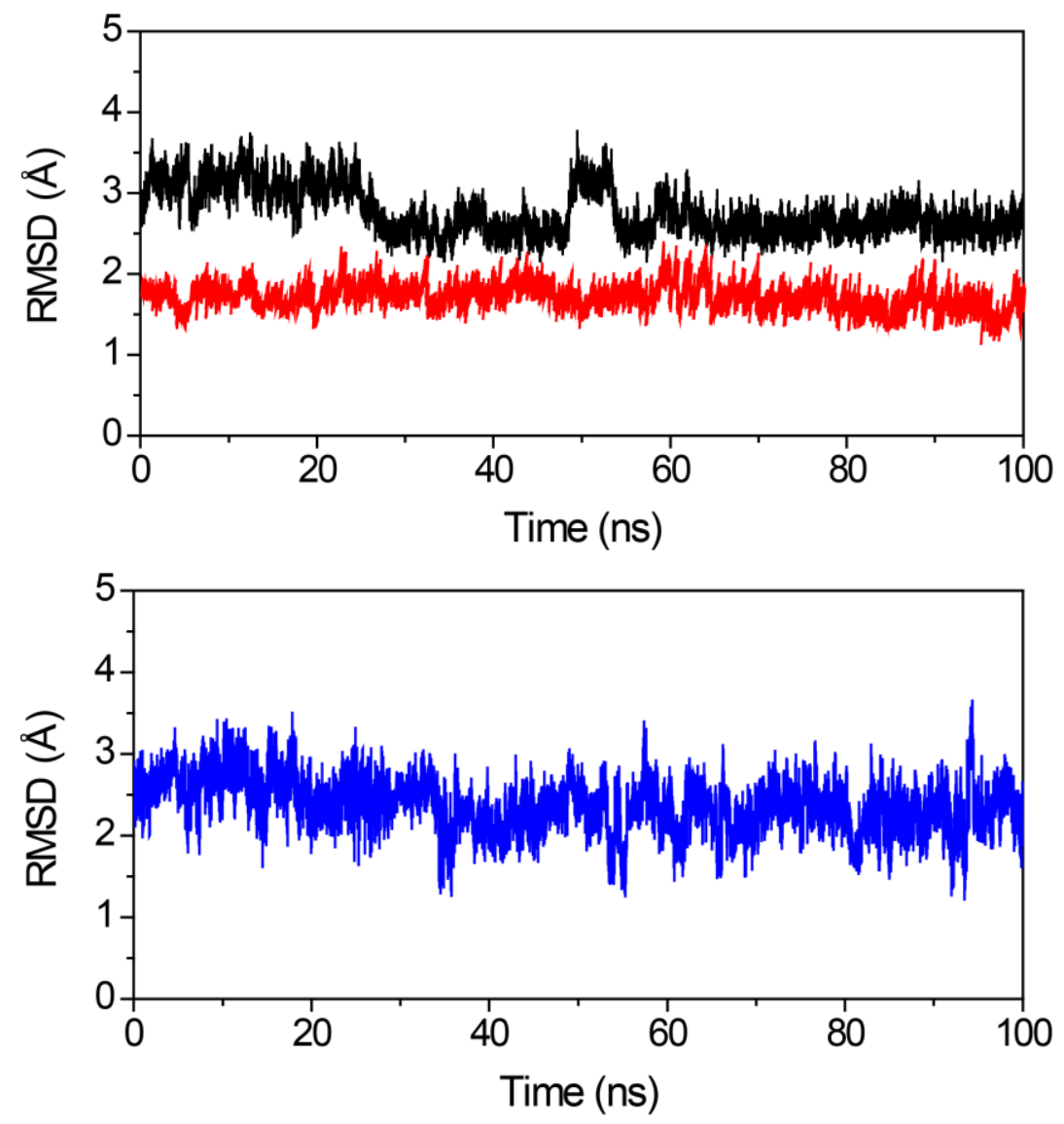

Figure S19. Time dependent root mean square deviation graphs (RMSD) of telomeric hybrid Gquadruplex DNA complexed with InPr2. RMSD of backbone (black), G-quartet (red), InPr2 (blue) were plotted against time. RMSDs were calculated at each ps during the $100 \mathrm{~ns}$ of MD simulations using ptraj module in AMBER 14. 


\section{Time dependent RMSD graphs of telomeric parallel quadruplex and InEt2}
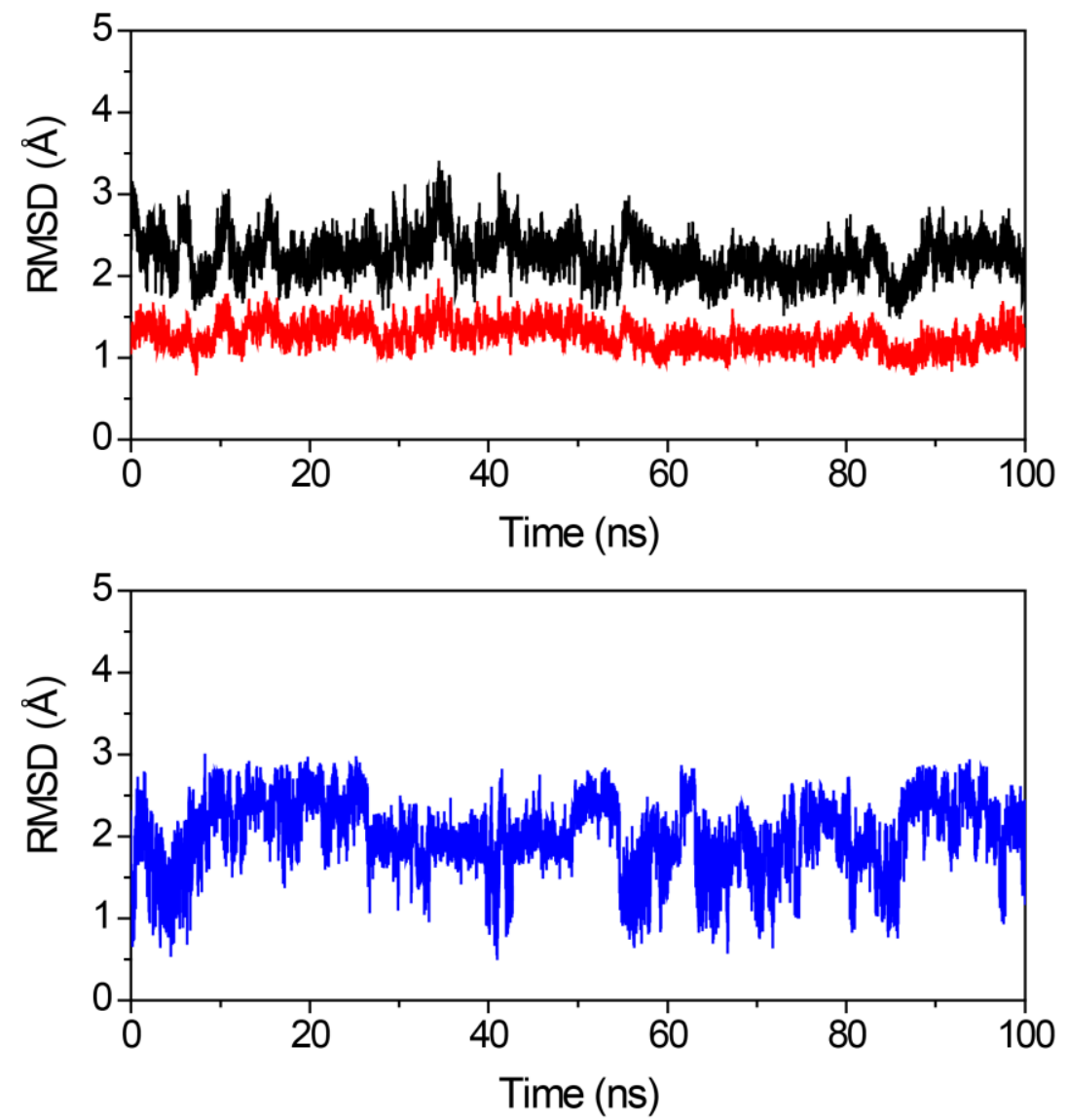

Figure S20. Time dependent root mean square deviation graphs (RMSD) of telomeric parallel Gquadruplex DNA complexed with InEt2. RMSD of backbone (black), G-quartet (red), InEt2 (blue) were plotted against time. RMSDs were calculated at each ps during the $100 \mathrm{~ns}$ of MD simulations using ptraj module in AMBER 14. 


\section{Time dependent RMSD graphs of telomeric parallel quadruplex and InPr2}
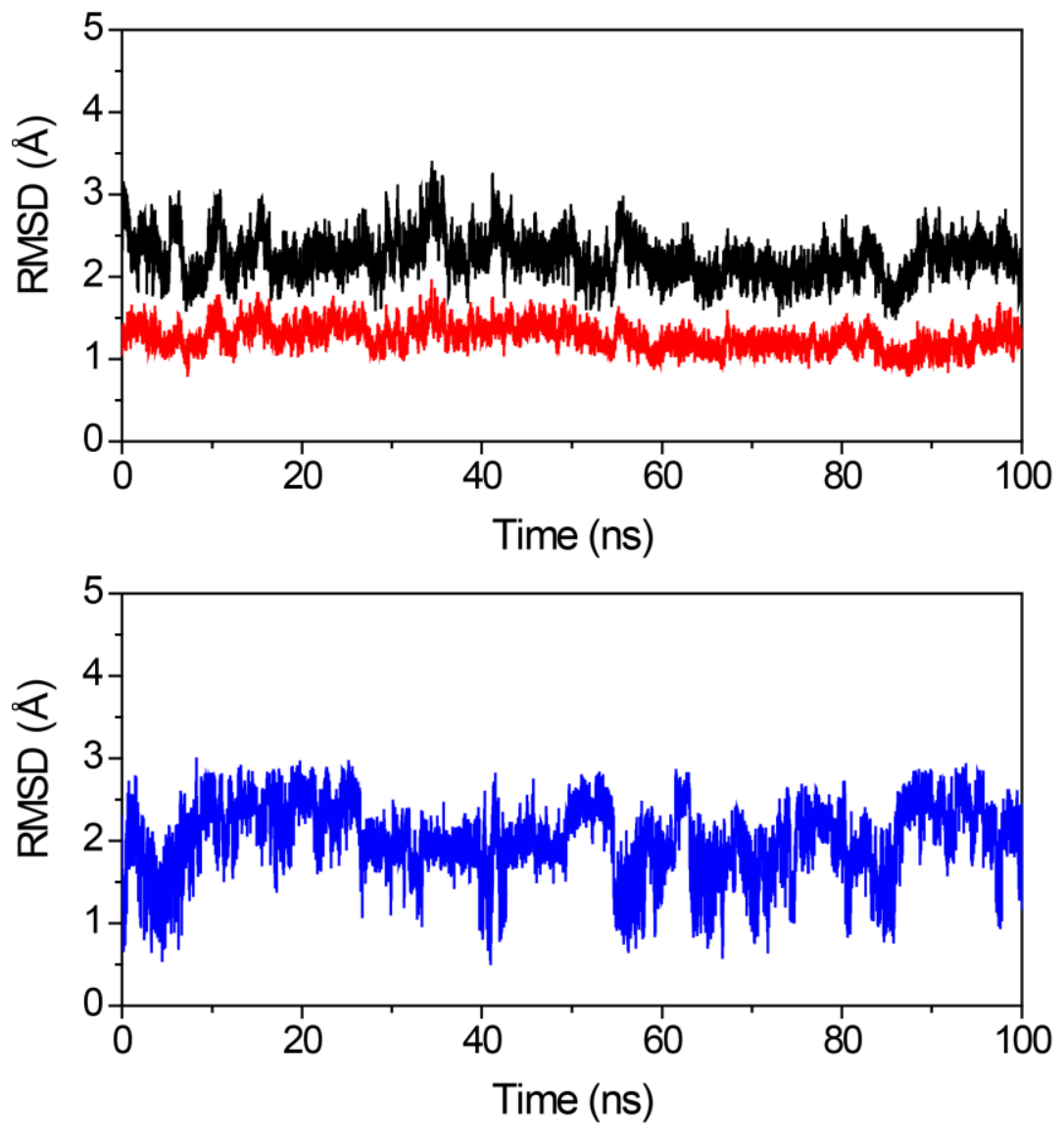

Figure S21. Time dependent root mean square deviation graphs (RMSD) of telomeric parallel Gquadruplex DNA complexed with InPr2. RMSD of backbone (black), G-quartet (red), InPr2 (blue) were plotted against time. RMSDs were calculated at each ps during the $100 \mathrm{~ns}$ of MD simulations using ptraj module in AMBER 14. 


\section{MD snapshots of InEt2 and InPr2 with telomeric parallel quadruplex DNA}

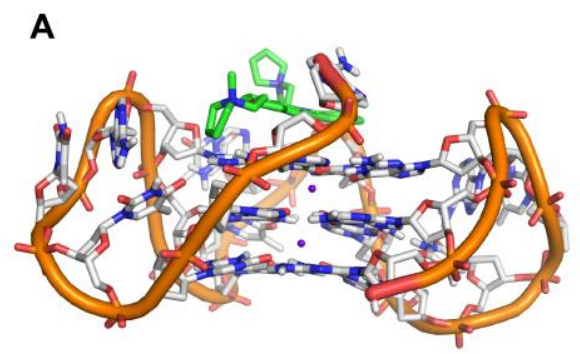

B
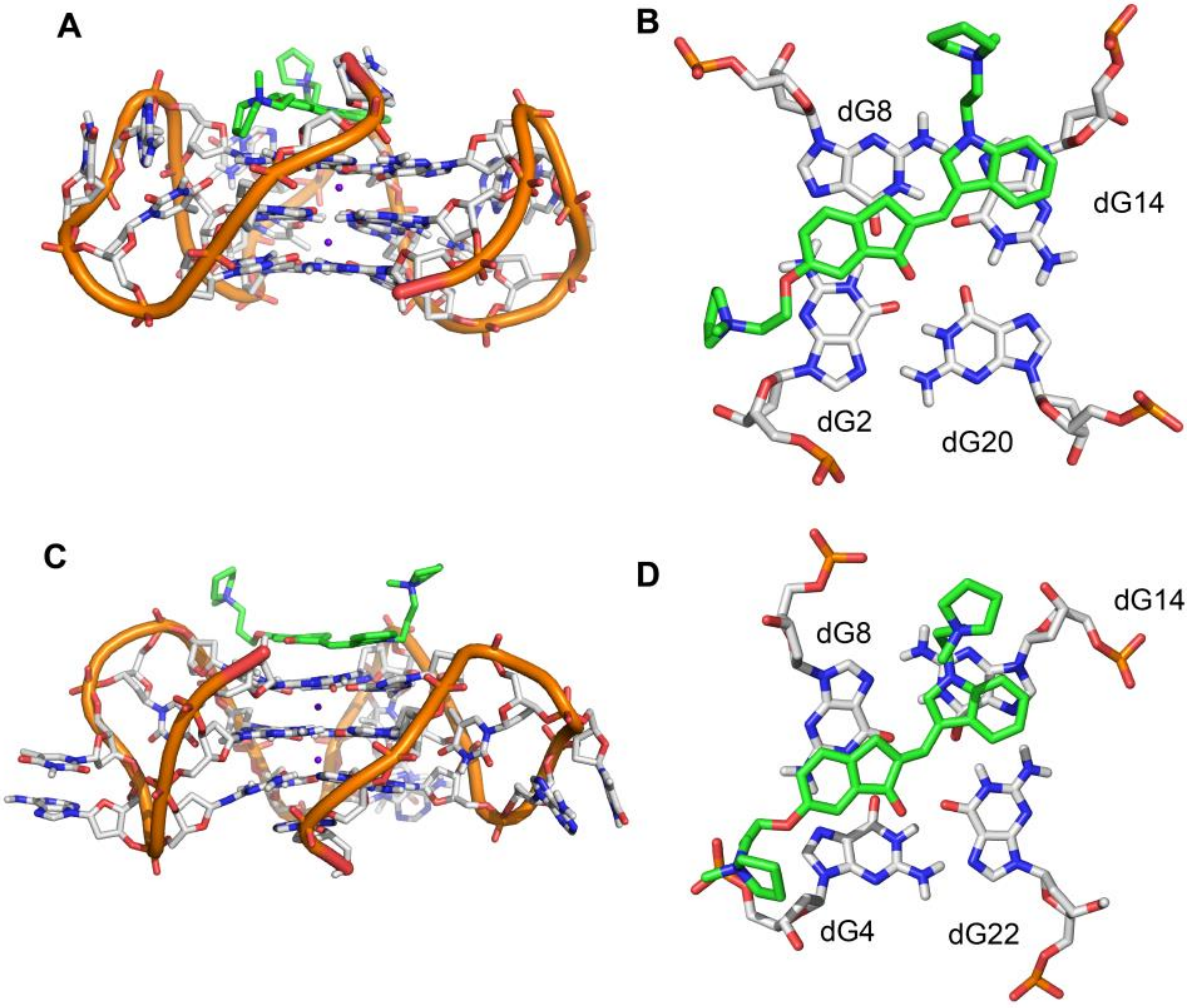

Figure S22. MD snapshots of InEt2 and InPr2 with telomeric parallel G-quadruplex DNA at $100 \mathrm{~ns}$ of the MD simulation. (A) Snapshot of InEt2 and telomeric parallel G-quadruplex DNA (full view); (B) Top G-quartet view of InEt2 and telomeric parallel G-quadruplex DNA; (C) MD snapshot of InPr2 and telomeric parallel G-quadruplex DNA (full view); and (D) Top G-quartet view of InPr2 and telomeric parallel G-quadruplex DNA. 


\section{MD snapshots of InEt 2 and InPr2 with telomeric antiparallel quadruplex DNA}

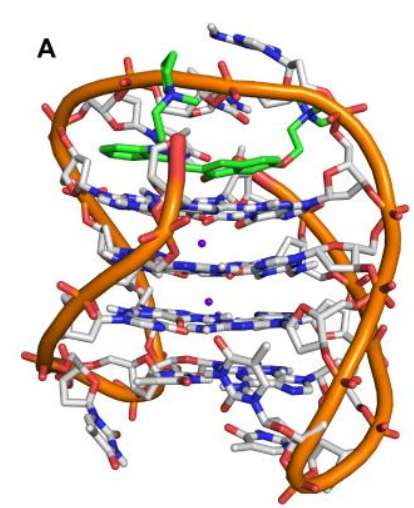

C

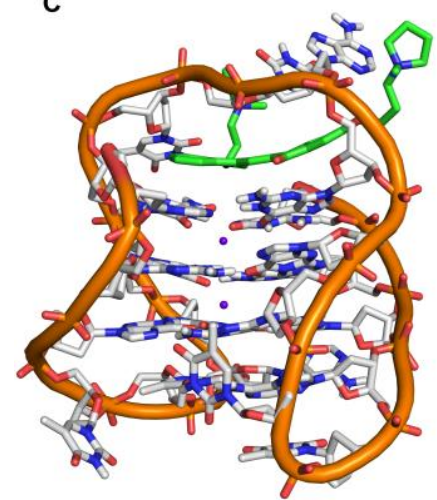

B

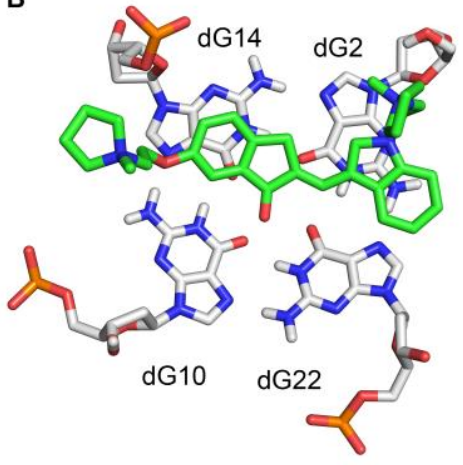

D

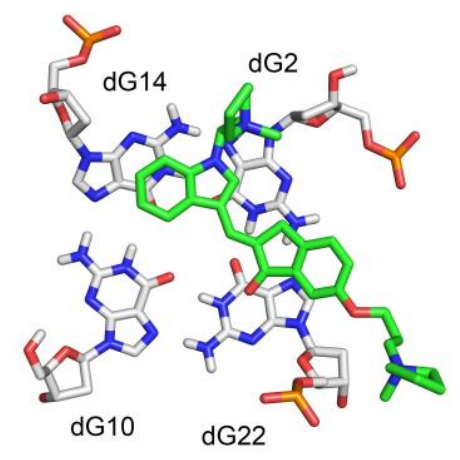

Figure S23. MD snapshots of InEt2 and InPr2 with telomeric antiparallel G-quadruplex DNA at 100 ns of the MD simulation. (A) Snapshot of InEt2 and telomeric antiparallel G-quadruplex DNA (full view); (B) Top G-quartet view of InEt2 and telomeric antiparallel G-quadruplex DNA; (C) MD snapshot of InPr2 and telomeric antiparallel G-quadruplex DNA (full view); and (D) Top G-quartet view of InPr2 and telomeric antiparallel G-quadruplex DNA. 


\section{MD snapshots of InEt2 and InPr2 with telomeric hybrid quadruplex DNA}

A

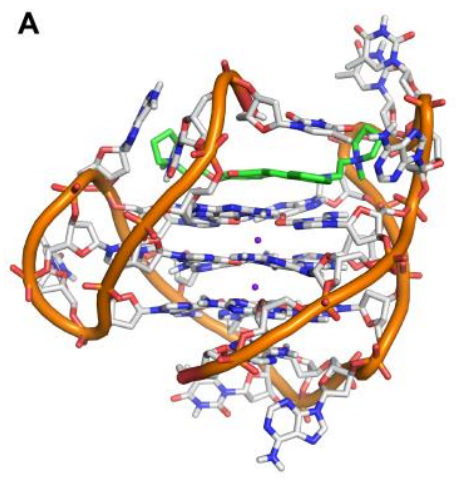

B
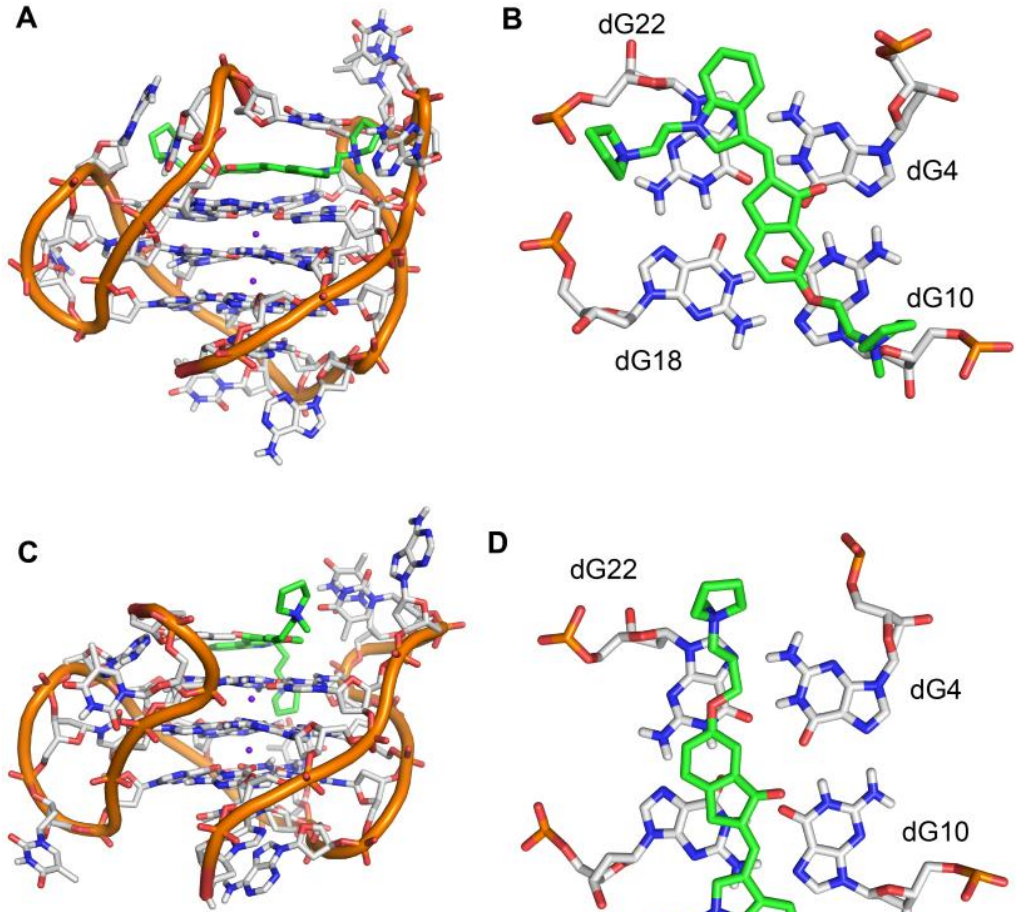

D

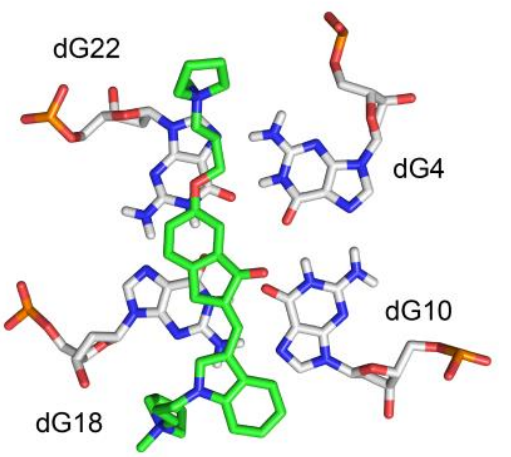

Figure S24. MD snapshots of InEt2 and InPr2 with telomeric hybrid G-quadruplex DNA at $100 \mathrm{~ns}$ of the MD simulation. (A) Snapshot of InEt2 and telomeric hybrid G-quadruplex DNA (full view); (B) Top G-quartet view of InEt2 and telomeric hybrid G-quadruplex DNA; (C) MD snapshot of InPr2 and telomeric hybrid G-quadruplex DNA (full view); and (D) Top G-quartet view of InPr2 and telomeric hybrid G-quadruplex DNA. 
Oligonucleotides used for biophysical and biochemical studies

\begin{tabular}{|c|c|}
\hline Description & Sequence \\
\hline Telomeric DNA & 5'-AGGGTTAGGGTTAGGGTTAGGG-3' \\
\hline Long telomeric DNA & $\begin{array}{l}\text { 5'-AGGGTTAGGGTTAGGGTTAGGG-TT-AGGGTTAGGGT } \\
\text { TAGGGTTAGGG-3' }\end{array}$ \\
\hline$c-M Y C$ DNA & 5'-TGAGGGTGGGTAGGGTGGGGAA-3' \\
\hline$c-K I T 1$ DNA & 5'-GGGAGGGCGCTGGGAGGAGGG-3' \\
\hline$c-K I T 2$ DNA & 5'-GGGCGGGCGCGAGGGAGGGG-3' \\
\hline Parallel quadruplex DNA & $\left(5^{\prime}-\mathrm{TGGGGT-3')_{4 }}\right.$ \\
\hline \multirow[t]{2}{*}{ DS17 } & 5'-CCAGTTCGTAGTAACCC-3' \\
\hline & 5'-GGGTTACTA CGAACTGG-3' \\
\hline DK33 & $\left(5^{\prime}-\mathrm{CGTAAATTTACG}-3\right)_{2}$ \\
\hline DK66 & $\left(5^{\prime}-\mathrm{CGCGAATTCGCG} \mathrm{-3')_{2 }}\right.$ \\
\hline DK100 & $\left(5^{\prime}-\mathrm{CGCGGGCCCGCG-3')_{2 }}\right.$ \\
\hline Primer for stop assay & 5'-ACGACTCACTATAGCAATTGCG-3' \\
\hline Template with $c-M Y C$ & 5'-TGAGGGTGGGGAGGGTGGGGAAGCCACCGCAATTG \\
\hline DNA & CTATAGTGAGTCGT-3' \\
\hline Template with mutated $c$ - & 5'-TGAGGGTGGGTAGAGTGGGTAAGCCACCGCAATTG \\
\hline$M Y C$ DNA & CTATAGTGAGTCGT-3' \\
\hline Template with telomeric & 5'-AGGGTTAGGGTTAGGGTTAGGGGCCACCGCAATTG \\
\hline DNA & CTATAGTGAGTCGT-3' \\
\hline
\end{tabular}

Table S1. List of oligonucleotides used for the experiments.

Thermodynamic parameters of telomeric quadruplex and duplex DNAs from ITC

\begin{tabular}{ccccccc}
\hline Ligand & $\begin{array}{c}K_{1} \\
\left(\mathrm{M}^{-1}\right) \times 10^{4}\end{array}$ & $\begin{array}{c}\Delta H_{1} \\
(\mathrm{kcal} / \mathrm{mol})\end{array}$ & $\begin{array}{c}\mathrm{T} \Delta S_{1} \\
(\mathrm{kcal} / \mathrm{mol})\end{array}$ & $\begin{array}{c}K_{2} \\
\left(\mathrm{M}^{-1}\right) \times 10^{4}\end{array}$ & $\begin{array}{c}\Delta H_{2} \\
(\mathrm{kcal} / \mathrm{mol})\end{array}$ & $\begin{array}{c}\mathrm{T} \Delta S_{2} \\
(\mathrm{kcal} / \mathrm{mol})\end{array}$ \\
\hline InEt2 & $0.6 \pm 0.05$ & $-20.6 \pm 1.5$ & -1.3 & $0.4 \pm 0.03$ & $5.8 \pm 2.0$ & 0.1 \\
InPr2 & $0.7 \pm 0.05$ & $-20.6 \pm 0.9$ & -1.3 & $0.3 \pm 0.03$ & $10.3 \pm 1.6$ & 1.3 \\
\hline \multicolumn{7}{c}{ Duplex-17 (DS17) } \\
\hline InEt2 & $1.2 \pm 0.05$ & $-100 \pm 3.9$ & 8.1 & $2.3 \pm 0.2$ & $153.6 \pm 5.4$ & 13.3 \\
\hline InPr2 & $2.2 \pm 0.2$ & $-8.9 \pm 0.3$ & -0.2 & $0.6 \pm 0.04$ & $-7.7 \pm 0.6$ & -0.2 \\
\hline Table S2. Thermodynamic parameters obtained from ITC experiment for the interaction of ligands \\
with telomeric quadruplex and duplex DNAs at 25 ${ }^{\circ} \mathrm{C}$. Best fit parameters obtained by sequential \\
binding model with Chi ${ }^{2}=8173$ and 6293 for InEt2 and InPr2 with telomeric DNA and Chi ${ }^{2}=8124$ \\
and 7860 for InEt2 and InPr2 with duplex DNA respectively
\end{tabular}




\section{Average RMSDs of G-Quadruplex DNAs and InEt 2 complex}

\begin{tabular}{ccc}
\hline $\begin{array}{c}\text { Heavy atoms of DNA and } \\
\text { ligand }\end{array}$ & $c$ - $M Y C$ G-quadruplex DNA & $c$-KIT1 G-quadruplex DNA \\
\hline G-quartet & $0.96 \pm 0.11$ & $1.17 \pm 0.16$ \\
DNA backbone & $1.98 \pm 0.29$ & $1.80 \pm 0.20$ \\
InEt2 & $2.22 \pm 0.45\left(5^{\prime}\right.$-InEt2) & $2.09 \pm 0.46\left(5^{\prime}\right.$-InEt2) \\
& $2.27 \pm 0.35$ (3'-InEt2) & $2.35 \pm 0.44$ (3'-InEt2) \\
\hline $\begin{array}{l}\text { Table S3. Average RMSD values (A) of the heavy atoms in the backbone, G-quartet of G-quadruplex } \\
\text { DNA complexed with InEt2. RMSDs were calculated at each ps from 100 ns of MD simulations } \\
\text { using ptraj module in AMBER 14. Errors indicate the standard deviation. }\end{array}$ \\
\hline
\end{tabular}

\section{Hoogsteen H-bond occupancies in G-quartet during MD simulations of InEt2}

\begin{tabular}{lcc}
\hline G-quartet & $\begin{array}{c}\text { Percentage occupancy } \\
(c-M Y C)\end{array}$ & $\begin{array}{c}\text { Percentage occupancy } \\
(c-K I T 1)\end{array}$ \\
\hline 5' quartet & $99.59 \%$ & $99.92 \%$ \\
Middle quartet & $99.09 \%$ & $98.84 \%$ \\
3' quartet & $99.83 \%$ & $99.67 \%$ \\
\hline
\end{tabular}

Table S4. The percentage occupancy of Hoogsteen hydrogen bond between the guanine bases present in each G-quartet. The occupancies were calculated at each ps during $100 \mathrm{~ns}$ of MD simulations using ptraj module in AMBER 14. 
Binding free energy components of InEt2-c-MYC quadruplex DNA complex

\begin{tabular}{|c|c|c|c|}
\hline \multirow[t]{2}{*}{ MD Simulations (100 ns) } & \multicolumn{3}{|c|}{$c$-MYC G-quadruplex DNA (PDB entry: 2L7V) } \\
\hline & Dual & 5'-InEt2 & 3'-InEt2 \\
\hline$\Delta \mathrm{E}_{\mathrm{ELEC}}$ & $-1765 \pm 26$ & $-875 \pm 19$ & $-990 \pm 22$ \\
\hline$\Delta \mathrm{E}_{\mathrm{VDW}}$ & $-126 \pm 6$ & $-64 \pm 3$ & $-61 \pm 5$ \\
\hline$\Delta \mathrm{E}_{\mathrm{MM}}\left(\Delta \mathrm{E}_{\mathrm{Elec}}+\Delta \mathrm{E}_{\mathrm{VDW}}\right)$ & $-1891 \pm 29$ & $-940 \pm 20$ & $-951 \pm 25$ \\
\hline$\Delta \mathrm{PB}_{\mathrm{np}}$ & $-13 \pm 0.5$ & $-7 \pm 0.3$ & $-7 \pm 0.5$ \\
\hline$\Delta \mathrm{PB}_{\mathrm{cal}}$ & $1798 \pm 27$ & $890 \pm 19$ & $908 \pm 23$ \\
\hline$\Delta \mathrm{PB}_{\text {solv }}\left(\Delta \mathrm{PB}_{\mathrm{np}}+\Delta \mathrm{PB}_{\text {cal }}\right)$ & $1785 \pm 27$ & $883 \pm 19$ & $902 \pm 23$ \\
\hline$\Delta H_{\mathrm{PB}}\left(\Delta \mathrm{E}_{\mathrm{MM}}+\Delta \mathrm{PB}_{\mathrm{solv}}\right)$ & $-106 \pm 6$ & $-57 \pm 4$ & $-50 \pm 4$ \\
\hline$\Delta \mathrm{GB}_{\mathrm{np}}$ & $-13 \pm 0.5$ & $-7 \pm 0.3$ & $-7 \pm 0.5$ \\
\hline$\Delta \mathrm{GB}_{\mathrm{cal}}$ & $1779 \pm 26$ & $881 \pm 18$ & $898 \pm 22$ \\
\hline$\Delta \mathrm{GB}_{\text {solv }}\left(\Delta \mathrm{GB}_{\mathrm{np}}+\Delta \mathrm{GB}_{\mathrm{cal}}\right)$ & $1766 \pm 25$ & $875 \pm 18$ & $891 \pm 22$ \\
\hline$\Delta H_{\mathrm{GB}}\left(\Delta \mathrm{E}_{\mathrm{MM}}+\Delta \mathrm{GB}_{\text {solv }}\right)$ & $-126 \pm 5$ & $-65 \pm 3$ & $-60 \pm 4$ \\
\hline$\Delta \mathrm{S}_{\text {TRANS }}$ & $-13.85 \pm 0.00$ & $-13.28 \pm 0.00$ & $-13.29 \pm 0.00$ \\
\hline$\Delta \mathrm{S}_{\mathrm{ROTA}}$ & $-13.19 \pm 0.02$ & $-11.64 \pm 0.03$ & $-11.62 \pm 0.04$ \\
\hline$\Delta \mathrm{S}_{\text {VIBR }}$ & $-0.55 \pm 7.86$ & $7.50 \pm 6.39$ & $7.08 \pm 6.59$ \\
\hline $\mathrm{T} \Delta S$ & $-26 \pm 8$ & $-17 \pm 6$ & $-18 \pm 7$ \\
\hline$\Delta G\left(\Delta H_{\mathrm{PB}}-\mathrm{T} \Delta S\right)$ & $-80 \pm 10$ & $-39 \pm 7$ & $-30 \pm 8$ \\
\hline
\end{tabular}

Table S5. Binding free energy components of $c-M Y C$ G-quadruplex DNA in complex with InEt2 calculated from last $15 \mathrm{~ns}$ of $100 \mathrm{~ns}$ MD simulations. The molecular mechanical energy calculations are calculated using MM/PB-GBSA and entropy calculations are carried using nmode in AMBER 14. $\Delta \mathrm{E}_{\mathrm{ELEC}}$ is the electrostatic interaction, $\Delta \mathrm{E}_{\mathrm{VDW}}$ is the Vander Waals contribution, $\Delta \mathrm{E}_{\mathrm{MM}}$ is the total molecular-mechanical energy $\left(\Delta \mathrm{E}_{\mathrm{ELEC}}+\Delta \mathrm{E}_{\mathrm{VDW}}+\Delta \mathrm{E}_{\text {ini }}\right.$ (zero for all)). $\Delta \mathrm{GB}_{\mathrm{np}}$ is the nonpolar contribution to the solvation energy. $\Delta H_{\mathrm{PB}}$ and $\Delta H_{\mathrm{GB}}$ are the electrostatic contributions to the solvation energy calculated; $\Delta \mathrm{PB}_{\text {solv }}$ and $\Delta \mathrm{GB}_{\text {solv }}$ are the total solvation energy. $\mathrm{T} \Delta S$ is solute entropic contribution, where $\mathrm{T}=$ temperature and $\Delta S$ is the sum of translational, rotational, and vibrational entropies. $\Delta G$ is the estimated binding free energy with solute entropic contribution $\left(\Delta H_{\mathrm{GB}}-\mathrm{T} \Delta S\right)$. All the values are reported in $\mathrm{kcal} \mathrm{mol}^{-1}$. 
Binding free energy components of InEt2-c-KIT1 quadruplex DNA complex

\begin{tabular}{|c|c|c|c|}
\hline \multirow[t]{2}{*}{ MD Simulations (100 ns) } & \multicolumn{3}{|c|}{ c-KIT1 G-quadruplex DNA (PDB entry: 2O3M) } \\
\hline & Dual & 5'-InEt2 & 3'-InEt2 \\
\hline$\Delta \mathrm{E}_{\mathrm{ELEC}}$ & $-1662 \pm 35$ & $-750 \pm 27$ & $-912 \pm 26$ \\
\hline$\Delta \mathrm{E}_{\mathrm{VDW}}$ & $-100 \pm 6$ & $-47 \pm 4$ & $-53 \pm 4$ \\
\hline$\Delta \mathrm{E}_{\mathrm{MM}}\left(\Delta \mathrm{E}_{\mathrm{Elec}}+\Delta \mathrm{E}_{\mathrm{VDW}}\right)$ & $-1762 \pm 39$ & $-797 \pm 30$ & $-964 \pm 29$ \\
\hline$\Delta \mathrm{PB}_{\mathrm{np}}$ & $-11 \pm 0.5$ & $-5 \pm 0.4$ & $-6 \pm 0.3$ \\
\hline$\Delta \mathrm{PB}_{\mathrm{cal}}$ & $1688 \pm 36$ & $762 \pm 27$ & $926 \pm 28$ \\
\hline$\Delta \mathrm{PB}_{\text {solv }}\left(\Delta \mathrm{PB}_{\mathrm{np}}+\Delta \mathrm{PB}_{\mathrm{cal}}\right)$ & $1677 \pm 35$ & $756 \pm 27$ & $921 \pm 28$ \\
\hline$\Delta H_{\mathrm{PB}}\left(\Delta \mathrm{E}_{\mathrm{mm}}+\Delta \mathrm{PB}_{\text {solv }}\right)$ & $-85 \pm 7$ & $-40 \pm 5$ & $-43 \pm 5$ \\
\hline$\Delta \mathrm{GB}_{\mathrm{np}}$ & $-11 \pm 0.5$ & $-5 \pm 0.4$ & $-6 \pm 0.3$ \\
\hline$\Delta \mathrm{GB}_{\mathrm{cal}}$ & $1671 \pm 35$ & $755 \pm 26$ & $916 \pm 26$ \\
\hline$\Delta \mathrm{GB}_{\text {solv }}\left(\Delta \mathrm{GB}_{\mathrm{np}}+\Delta \mathrm{GB}_{\text {cal }}\right)$ & $1660 \pm 34$ & $750 \pm 26$ & $910 \pm 26$ \\
\hline$\Delta H_{\mathrm{GB}}\left(\Delta \mathrm{E}_{\mathrm{MM}}+\Delta \mathrm{GB}_{\text {solv }}\right)$ & $-102 \pm 6$ & $-47 \pm 5$ & $-54 \pm 5$ \\
\hline$\Delta \mathrm{S}_{\text {TRANS }}$ & $-13.84 \pm 0.00$ & $-13.28 \pm 0.00$ & $-13.28 \pm 0.00$ \\
\hline$\Delta \mathrm{S}_{\mathrm{ROTA}}$ & $-13.21 \pm 0.03$ & $-11.61 \pm 0.04$ & $-11.63 \pm 0.06$ \\
\hline$\Delta \mathrm{S}_{\text {VIBR }}$ & $-0.38 \pm 7.16$ & $7.87 \pm 5.87$ & $7.35 \pm 5.74$ \\
\hline $\mathrm{T} \Delta S$ & $-27 \pm 7$ & $-17 \pm 6$ & $-18 \pm 6$ \\
\hline$\Delta G\left(\Delta H_{\mathrm{PB}}-\mathrm{T} \Delta S\right)$ & $-58 \pm 7$ & $-23 \pm 5$ & $-26 \pm 5$ \\
\hline
\end{tabular}

Table S6. Binding free energy components of $c$-KIT1 G-quadruplex DNA in complex with InEt2 calculated from last $15 \mathrm{~ns}$ of $100 \mathrm{~ns}$ MD simulations. The molecular mechanical energy calculations are calculated using MM/PB-GBSA and entropy calculations are carried using nmode in AMBER 14. $\Delta \mathrm{E}_{\mathrm{ELEC}}$ is the electrostatic interaction, $\Delta \mathrm{E}_{\mathrm{VDW}}$ is the Vander Waals contribution, $\Delta \mathrm{E}_{\mathrm{MM}}$ is the total molecular-mechanical energy $\left(\Delta \mathrm{E}_{\mathrm{ELEC}}+\Delta \mathrm{E}_{\mathrm{VDW}}+\Delta \mathrm{E}_{\text {ini }}\right.$ (zero for all)). $\Delta \mathrm{GB}_{\mathrm{np}}$ is the nonpolar contribution to the solvation energy. $\Delta H_{\mathrm{PB}}$ and $\Delta H_{\mathrm{GB}}$ are the electrostatic contributions to the solvation energy calculated; $\Delta \mathrm{PB}_{\text {solv }}$ and $\Delta \mathrm{GB}_{\text {solv }}$ are the total solvation energy. $\mathrm{T} \Delta S$ is solute entropic contribution, where $\mathrm{T}=$ temperature and $\Delta S$ is the sum of translational, rotational, and vibrational entropies. $\Delta G$ is the estimated binding free energy with solute entropic contribution $\left(\Delta H_{\mathrm{GB}}-\mathrm{T} \Delta S\right)$. All the values are reported in $\mathrm{kcal} \mathrm{mol}^{-1}$. 
Binding free energy components of InEt2-telomeric G-quadruplex DNA complexes

\begin{tabular}{|c|c|c|c|}
\hline \multirow{2}{*}{$\begin{array}{l}\text { MD Simulations } \\
\qquad(100 \mathrm{~ns})\end{array}$} & \multicolumn{3}{|c|}{ Telomeric G-quadruplex DNA } \\
\hline & Parallel & Antiparallel & Hybrid \\
\hline$\Delta \mathrm{E}_{\text {ELEC }}$ & $-747 \pm 22$ & $-742 \pm 25$ & $-722 \pm 26$ \\
\hline$\Delta \mathrm{EVDW}_{\mathrm{VD}}$ & $-43 \pm 3$ & $-39 \pm 5$ & $-37 \pm 4$ \\
\hline$\Delta \mathrm{E}_{\mathrm{MM}}\left(\Delta \mathrm{E}_{\text {Elec }}+\Delta \mathrm{E}_{\mathrm{VDW}}\right)$ & $-790 \pm 26$ & $-781 \pm 23$ & $-759 \pm 29$ \\
\hline$\Delta \mathrm{PB}_{\mathrm{np}}$ & $-6 \pm 0.3$ & $-7 \pm 0.5$ & $-5 \pm 0.3$ \\
\hline$\Delta \mathrm{PB}_{\mathrm{cal}}$ & $752 \pm 27$ & $749 \pm 29$ & $726 \pm 28$ \\
\hline$\Delta \mathrm{PB}_{\text {solv }}\left(\Delta \mathrm{PB}_{\mathrm{np}}+\Delta \mathrm{PB}_{\mathrm{cal}}\right)$ & $746 \pm 27$ & $742 \pm 24$ & $719 \pm 28$ \\
\hline$\Delta H_{\mathrm{PB}}\left(\Delta \mathrm{E}_{\mathrm{mm}}+\Delta \mathrm{PB}_{\mathrm{solv}}\right)$ & $-44 \pm 5$ & $-39 \pm 5$ & $-40 \pm 5$ \\
\hline$\Delta \mathrm{S}_{\text {TRANS }}$ & $-13.28 \pm 0.00$ & $-13.28 \pm 0.00$ & $-13.28 \pm 0.00$ \\
\hline$\Delta \mathrm{S}_{\mathrm{ROTA}}$ & $-12.61 \pm 0.04$ & $-12.61 \pm 0.04$ & $-12.63 \pm 0.06$ \\
\hline$\Delta \mathrm{S}_{\mathrm{VIBR}}$ & $5.7 \pm 1.2$ & $5.8 \pm 1.2$ & $3.8 \pm 1$ \\
\hline $\mathrm{T} \Delta S$ & $-20 \pm 4$ & $-20 \pm 4$ & $-22 \pm 5$ \\
\hline$\Delta G\left(\Delta H_{\mathrm{PB}}-\mathrm{T} \Delta S\right)$ & $-24 \pm 3$ & $-19 \pm 3$ & $-20 \pm 4$ \\
\hline
\end{tabular}

Table S7. Binding free energy components of telomeric G-quadruplex DNA toplogies in complex with InEt2 calculated from last $15 \mathrm{~ns}$ of $100 \mathrm{~ns}$ MD simulations. The molecular mechanical energy calculations are calculated using MM/GBSA and entropy calculations are carried using nmode in AMBER 14. All the values are reported in $\mathrm{kcal} \mathrm{mol}^{-1}$. 
Binding free energy components of InPr2-telomeric G-quadruplex DNA complexes

\begin{tabular}{|c|c|c|c|}
\hline \multirow{2}{*}{$\begin{array}{l}\text { MD Simulations } \\
\text { (100 ns) }\end{array}$} & \multicolumn{3}{|c|}{ Telomeric G-quadruplex DNA } \\
\hline & Parallel & Antiparallel & Hybrid \\
\hline$\Delta \mathrm{E}_{\text {ELEC }}$ & $-745 \pm 22$ & $-739 \pm 25$ & $-732 \pm 24$ \\
\hline$\Delta \mathrm{EVDW}_{\mathrm{VDW}}$ & $-41 \pm 3$ & $-39 \pm 5$ & $-38 \pm 4$ \\
\hline$\Delta \mathrm{E}_{\mathrm{MM}}\left(\Delta \mathrm{E}_{\mathrm{Elec}}+\Delta \mathrm{E}_{\mathrm{VDW}}\right)$ & $-786 \pm 26$ & $-768 \pm 23$ & $-770 \pm 27$ \\
\hline$\Delta \mathrm{PB}_{\mathrm{np}}$ & $-5 \pm 0.3$ & $-6 \pm 0.5$ & $-6 \pm 0.5$ \\
\hline$\Delta \mathrm{PB}_{\mathrm{cal}}$ & $748 \pm 27$ & $730 \pm 29$ & $736 \pm 25$ \\
\hline$\Delta \mathrm{PB}_{\text {solv }}\left(\Delta \mathrm{PB}_{\mathrm{np}}+\Delta \mathrm{PB}_{\mathrm{cal}}\right)$ & $743 \pm 27$ & $724 \pm 24$ & $730 \pm 24$ \\
\hline$\Delta H_{\mathrm{PB}}\left(\Delta \mathrm{E}_{\mathrm{mm}}+\Delta \mathrm{PB}_{\text {solv }}\right)$ & $-43 \pm 5$ & $-44 \pm 5$ & $-40 \pm 5$ \\
\hline$\Delta \mathrm{S}_{\text {TRANS }}$ & $-13.62 \pm 0.00$ & $-13.62 \pm 0.00$ & $-13.28 \pm 0.00$ \\
\hline$\Delta \mathrm{S}_{\mathrm{ROTA}}$ & $-12.82 \pm 0.04$ & $-12.85 \pm 0.04$ & $-12.63 \pm 0.06$ \\
\hline$\Delta \mathrm{S}_{\mathrm{VIBR}}$ & $5.7 \pm 1.2$ & $6.8 \pm 1.2$ & $3.8 \pm 1$ \\
\hline $\mathrm{T} \Delta S$ & $-21 \pm 4$ & $-20 \pm 4$ & $-22 \pm 5$ \\
\hline$\Delta G\left(\Delta H_{\mathrm{PB}}-\mathrm{T} \Delta S\right)$ & $-22 \pm 3$ & $-24 \pm 3$ & $-22 \pm 4$ \\
\hline $\begin{array}{l}\text { Table S8. Binding free ene } \\
\text { InPr2 calculated from la } \\
\text { calculations are calculated } \\
\text { AMBER } 14 \text {. All the values }\end{array}$ & $\begin{array}{l}\text { mponents of te } \\
\text { ns of } 100 \mathrm{~ns} \\
\text { MM/PBSA a } \\
\text { orted in kcal n }\end{array}$ & $\begin{array}{l}\text {-quadruplex DN } \\
\text { dlations. The m } \\
\text { y calculations }\end{array}$ & $\begin{array}{l}\text { gies in complex } \\
\text { mechanical er } \\
\text { ied using nmor }\end{array}$ \\
\hline
\end{tabular}

Percentage Life time occupancies of stacking interactions over 100 ns of MD simulations

Telomeric G-quadruplex DNA

Parallel Antiparallel Hybrid

\begin{tabular}{llcc}
\hline InEt2 & $42 \%$ & $31 \%$ & $30 \%$ \\
InPr2 & $46 \%$ & $29 \%$ & $23 \%$
\end{tabular}

Table S9. Percentage life-time occupancies of stacking interaction between G-quartet and the ligand over the $100 \mathrm{~ns}$ time of MD simulations. This analysis was carried out using CPPTRAJ in AMBER 14. The cut-off distance between the center of mass is $<3.7 \AA$ and the angle between the planes of the residues is $<30^{\circ}$. 
Page S29

${ }^{1} \mathrm{H} \&{ }^{13} \mathrm{C}$ spectra of compound 2 ( $\mathrm{G}$ - Grease)
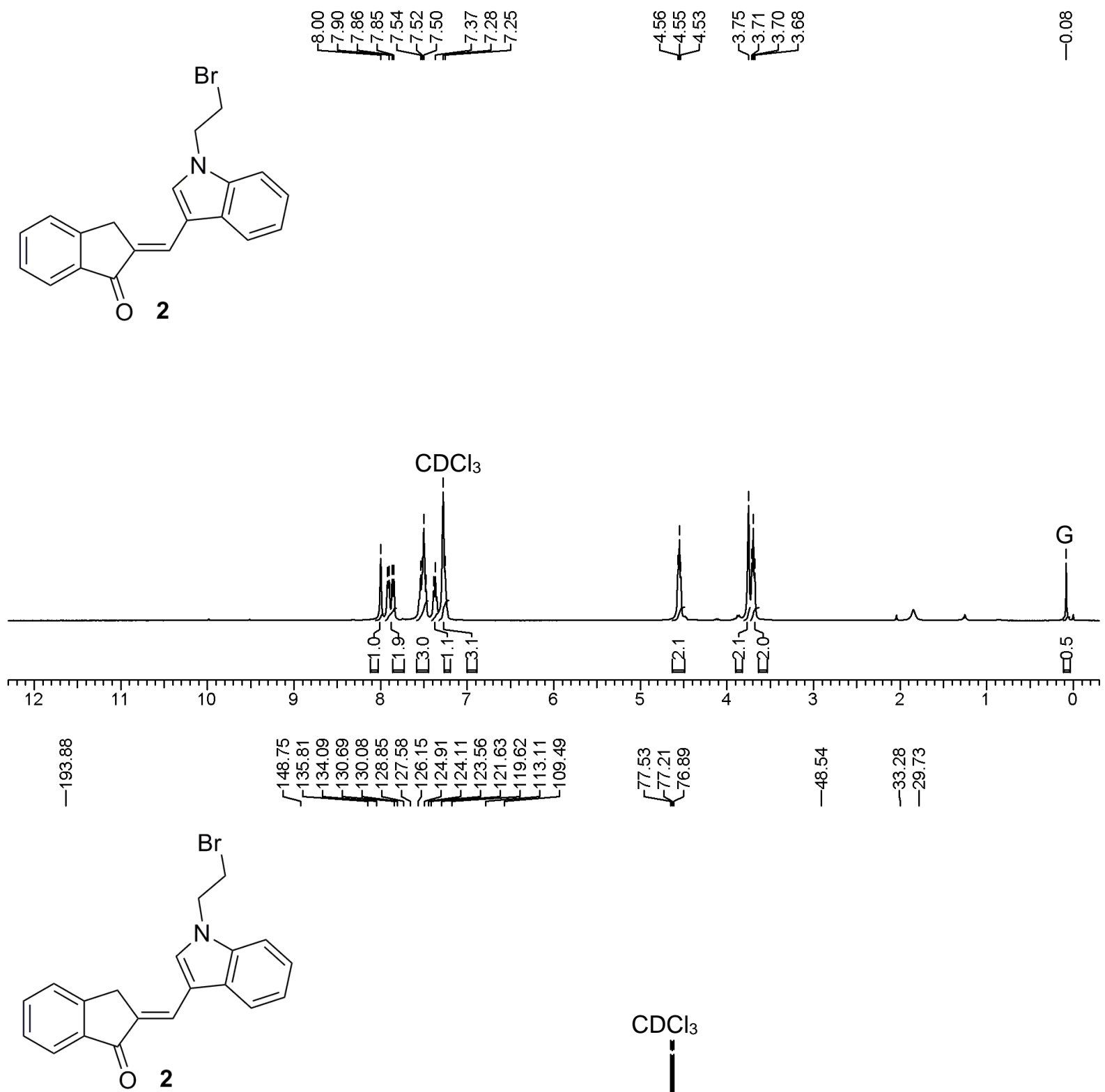

$\mathrm{CDCl}_{3}$

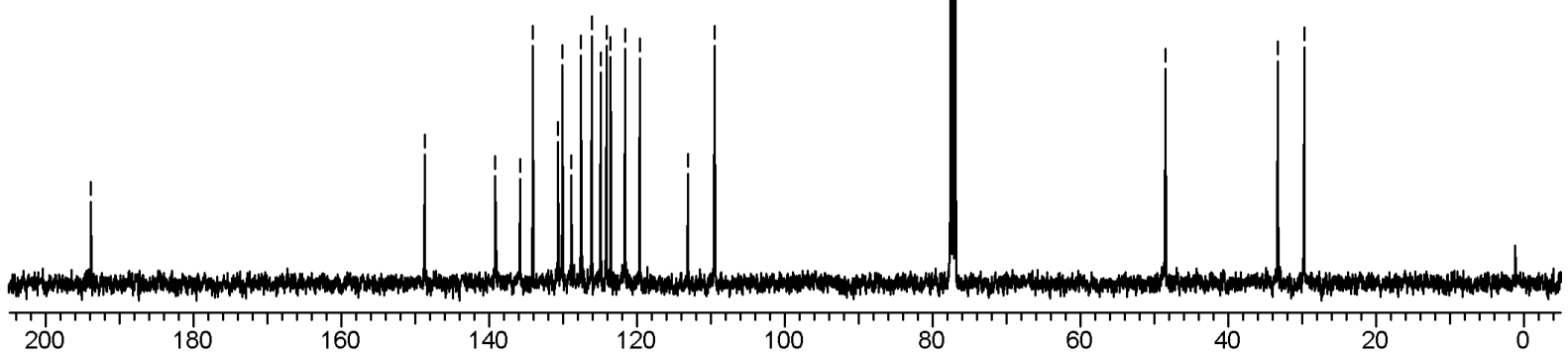


Page S30

${ }^{1} \mathrm{H} \&{ }^{13} \mathrm{C}$ spectra of compound 3

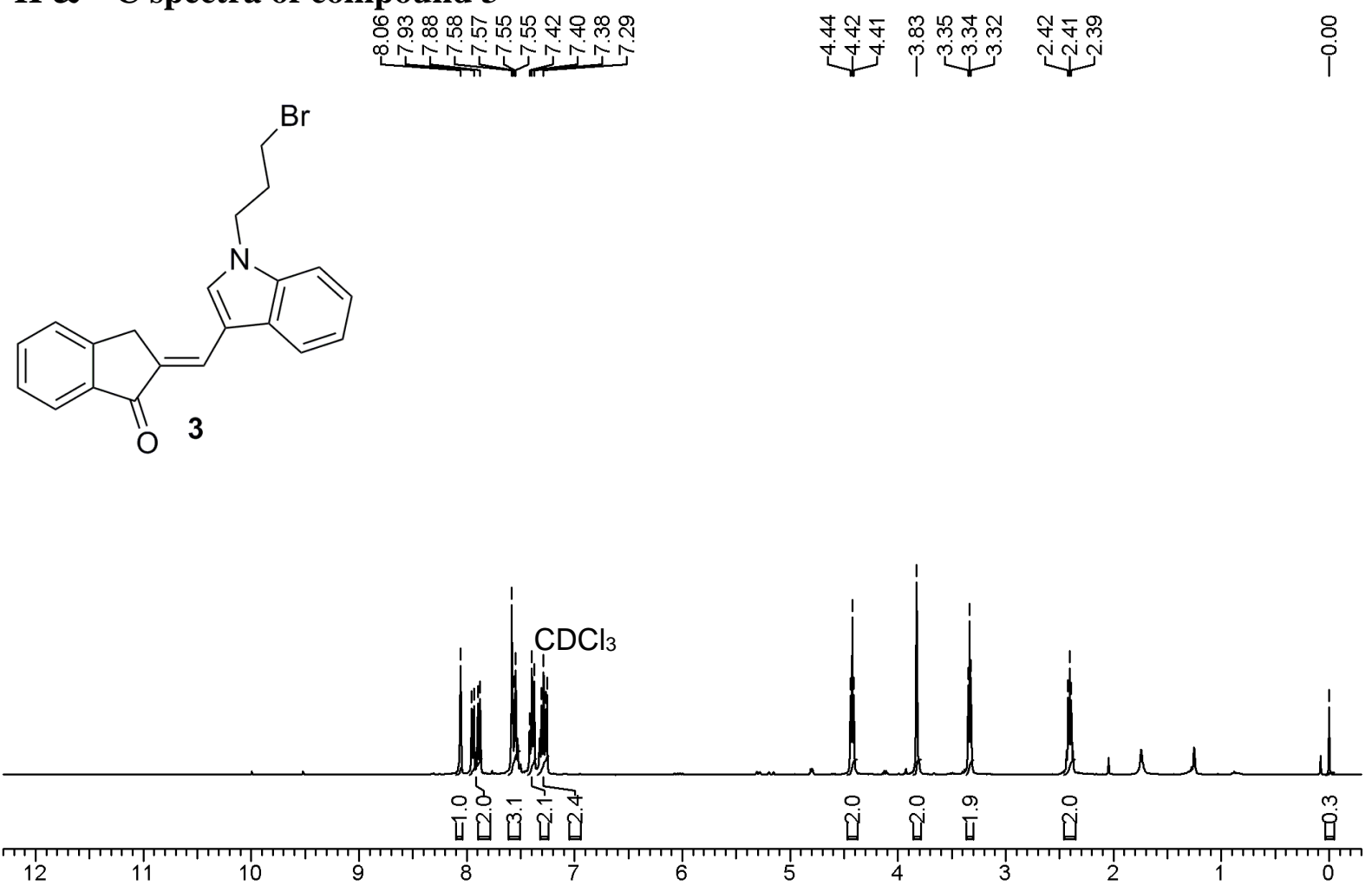

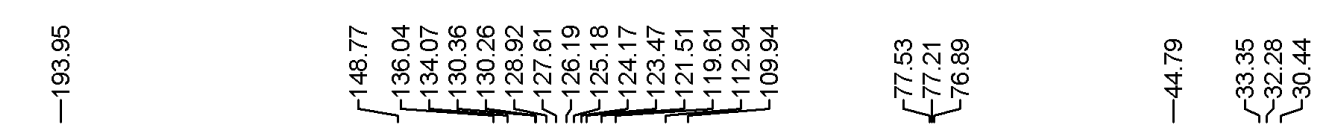<smiles>O=C1/C(=C/c2cn(CCCBr)c3ccccc23)Cc2ccccc21</smiles>

$\mathrm{CDCl}_{3}$

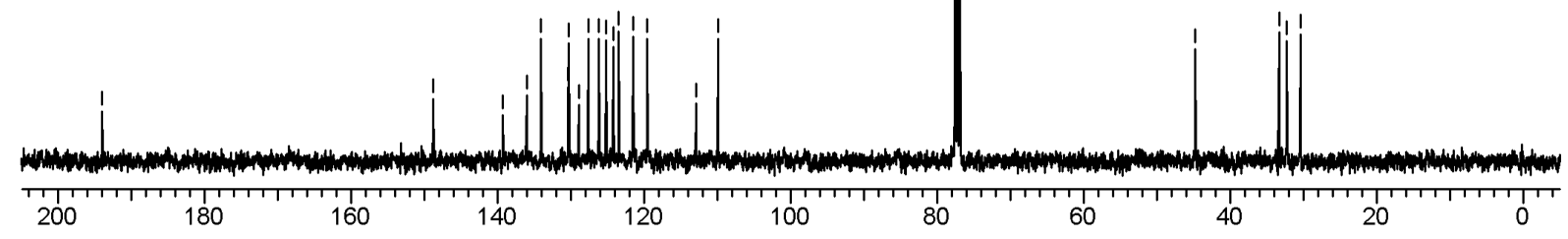


Page S31

${ }^{1} \mathrm{H} \&{ }^{13} \mathrm{C}$ spectra of compound 4

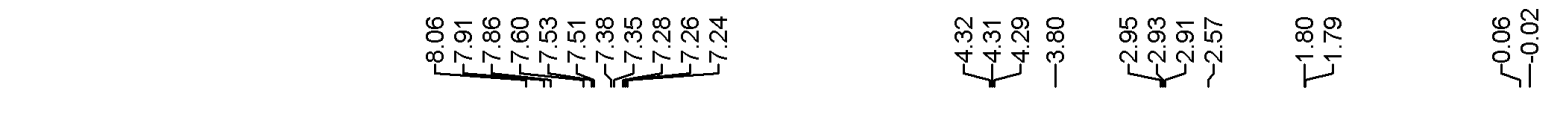<smiles>O=C1C(=Cc2cn(CCN3CCCC3)c3ccccc23)Cc2ccccc21</smiles>

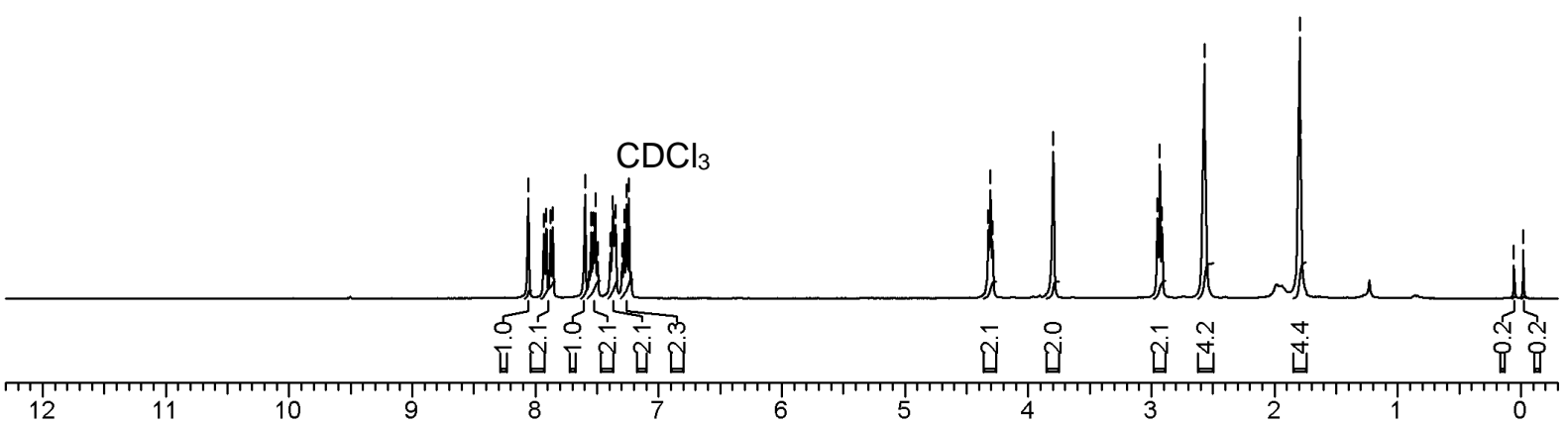

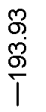

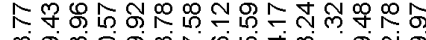

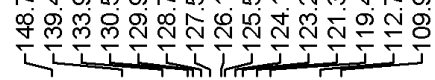

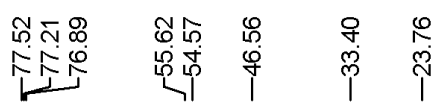<smiles>O=C1/C(=C/c2cn(CCN3CCCC3)c3ccccc23)Cc2ccccc21</smiles>

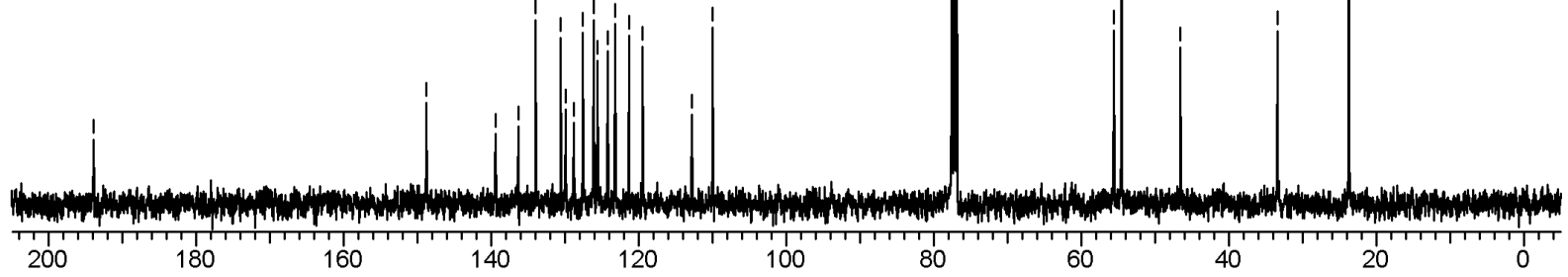


Page S32

${ }^{1} \mathrm{H} \&{ }^{13} \mathrm{C}$ spectra of compound 5 (G - Grease)
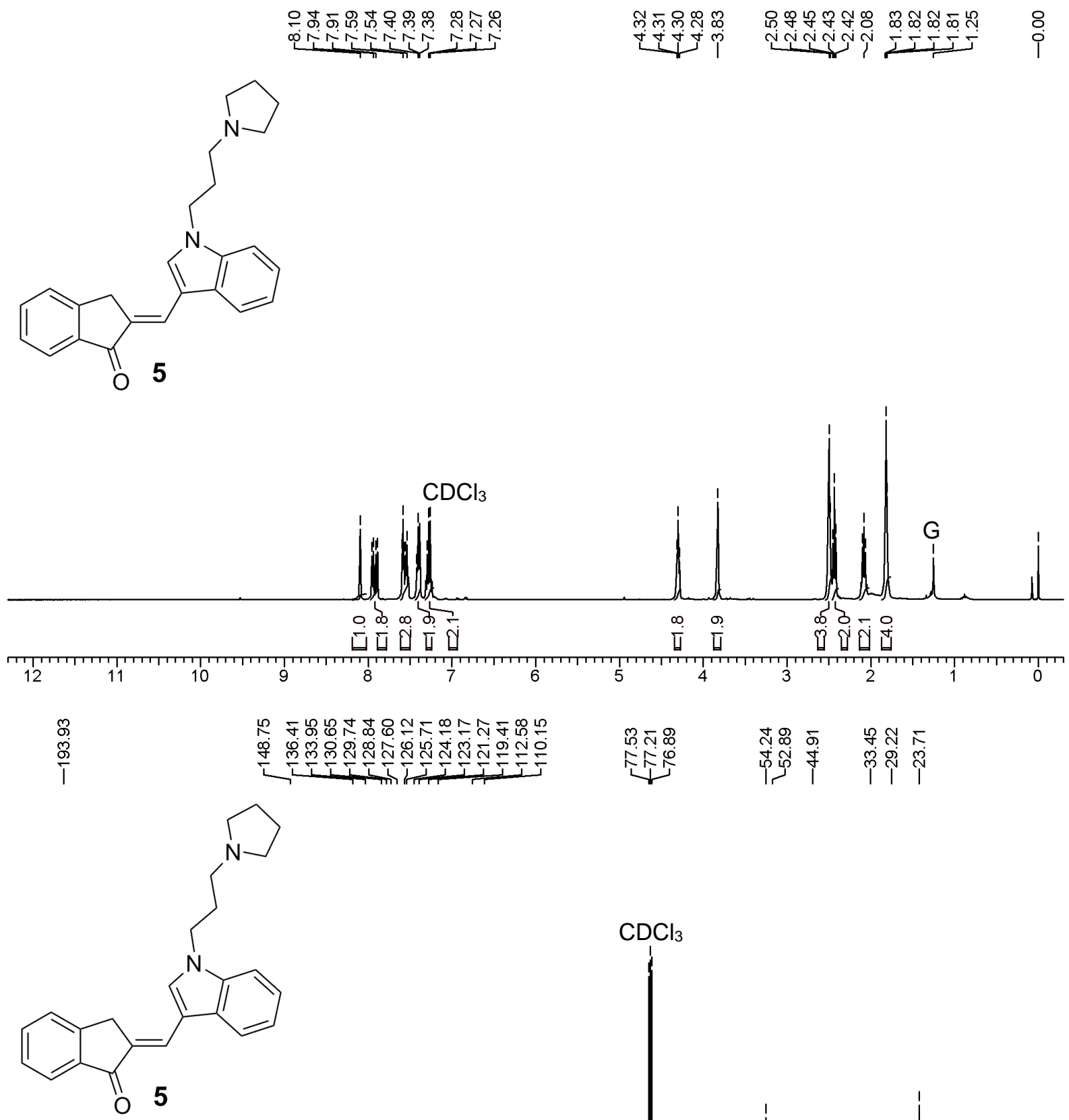

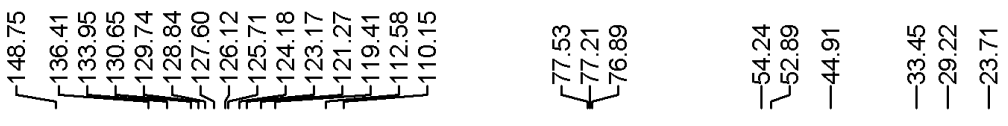


${ }^{1} \mathrm{H} \&{ }^{13} \mathrm{C}$ spectra of compound InEt1
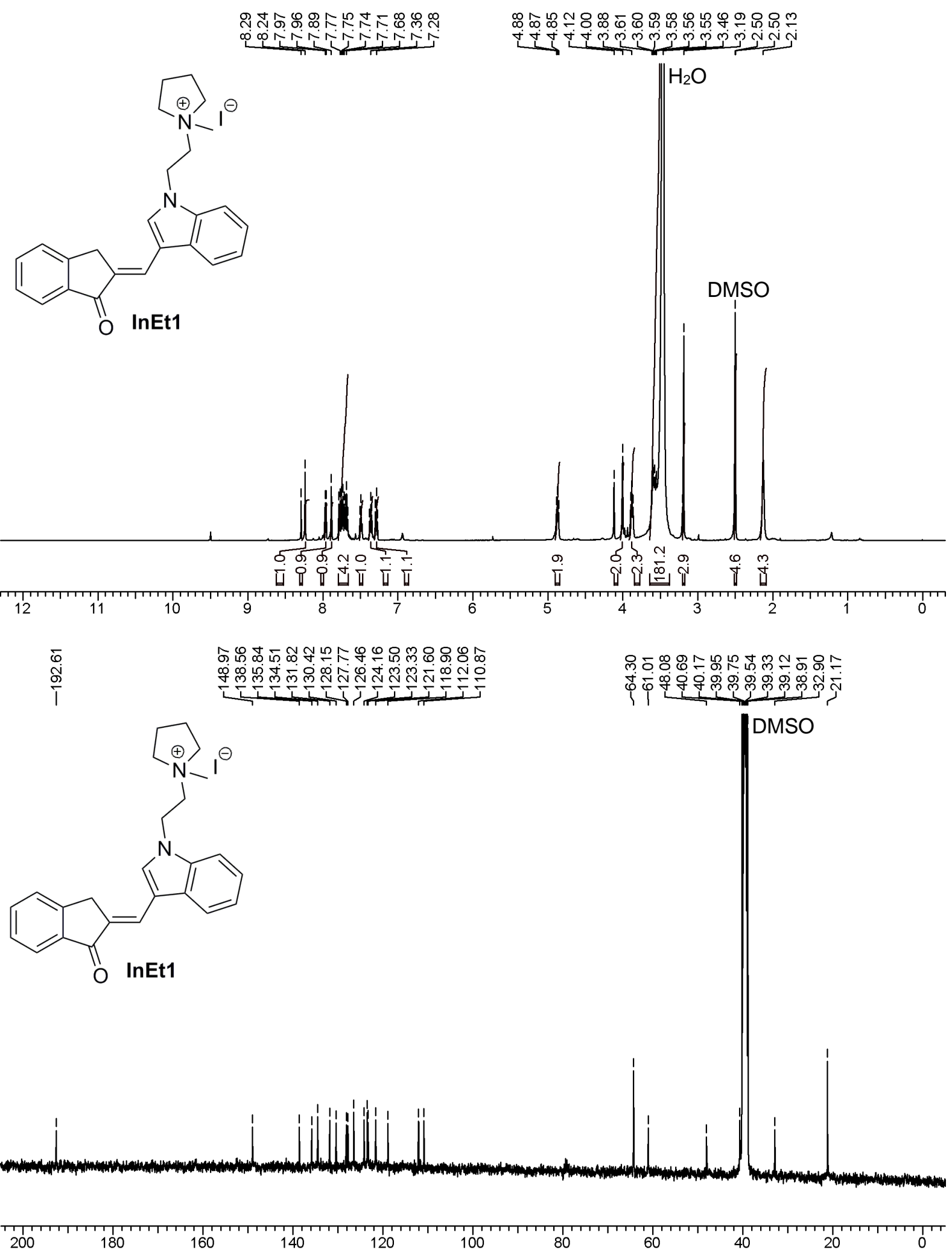
${ }^{1} \mathrm{H} \&{ }^{13} \mathrm{C}$ spectra of compound InPr1

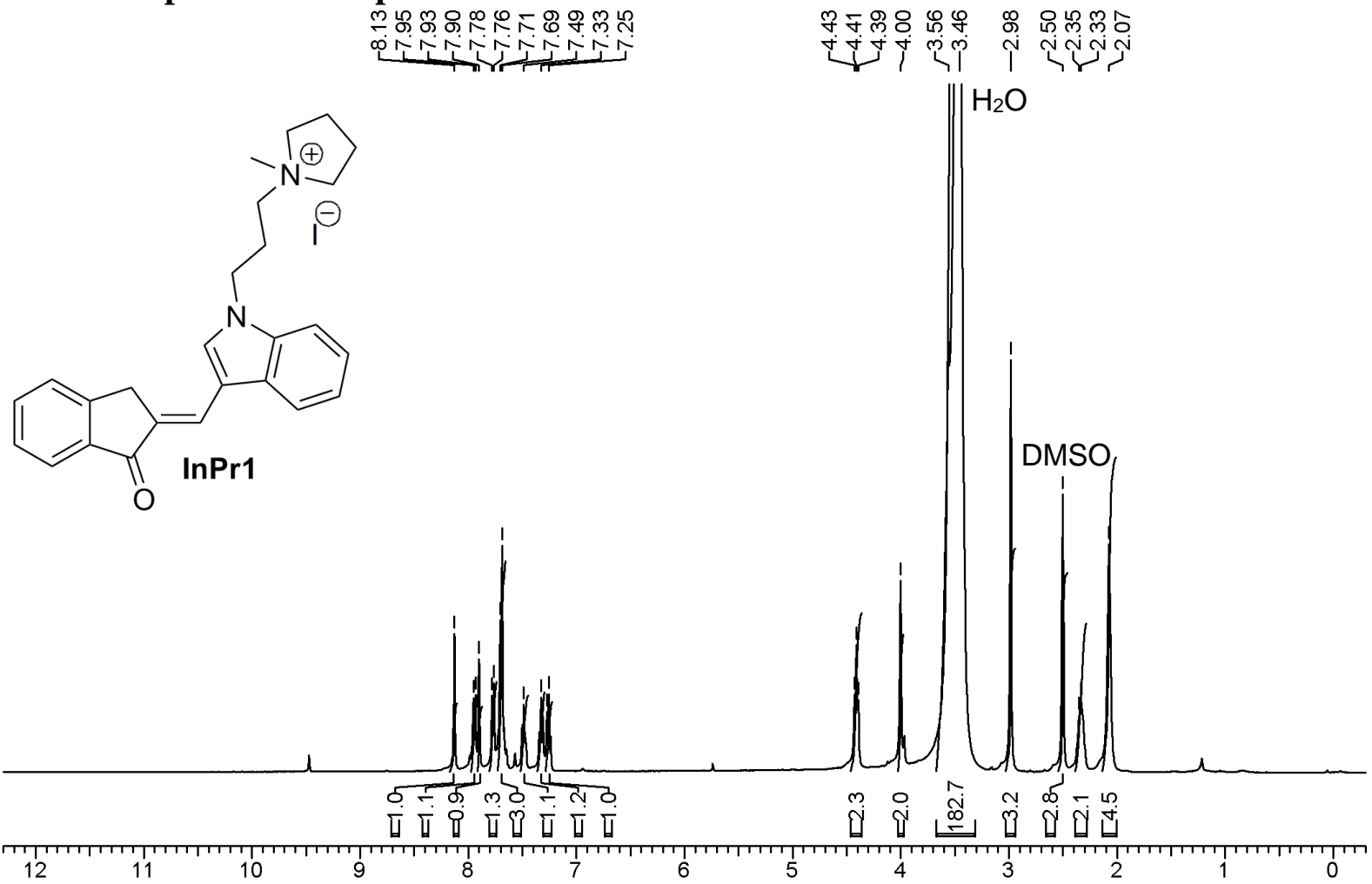<smiles>CC(C)[N+]1(CCCn2cc(/C=C3\Cc4ccccc4C3=O)c3ccccc32)CCCC1</smiles>

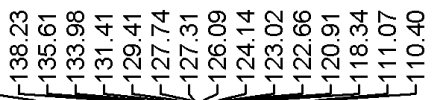

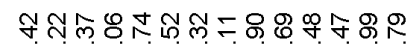

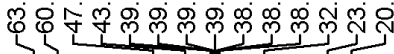

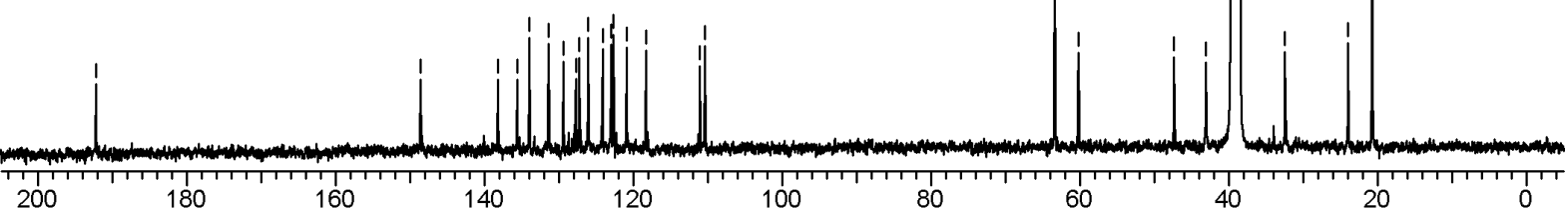


Page S35

${ }^{1} \mathrm{H} \&{ }^{13} \mathrm{C}$ spectra of compound 10 ( $\mathrm{G}$ - Grease)
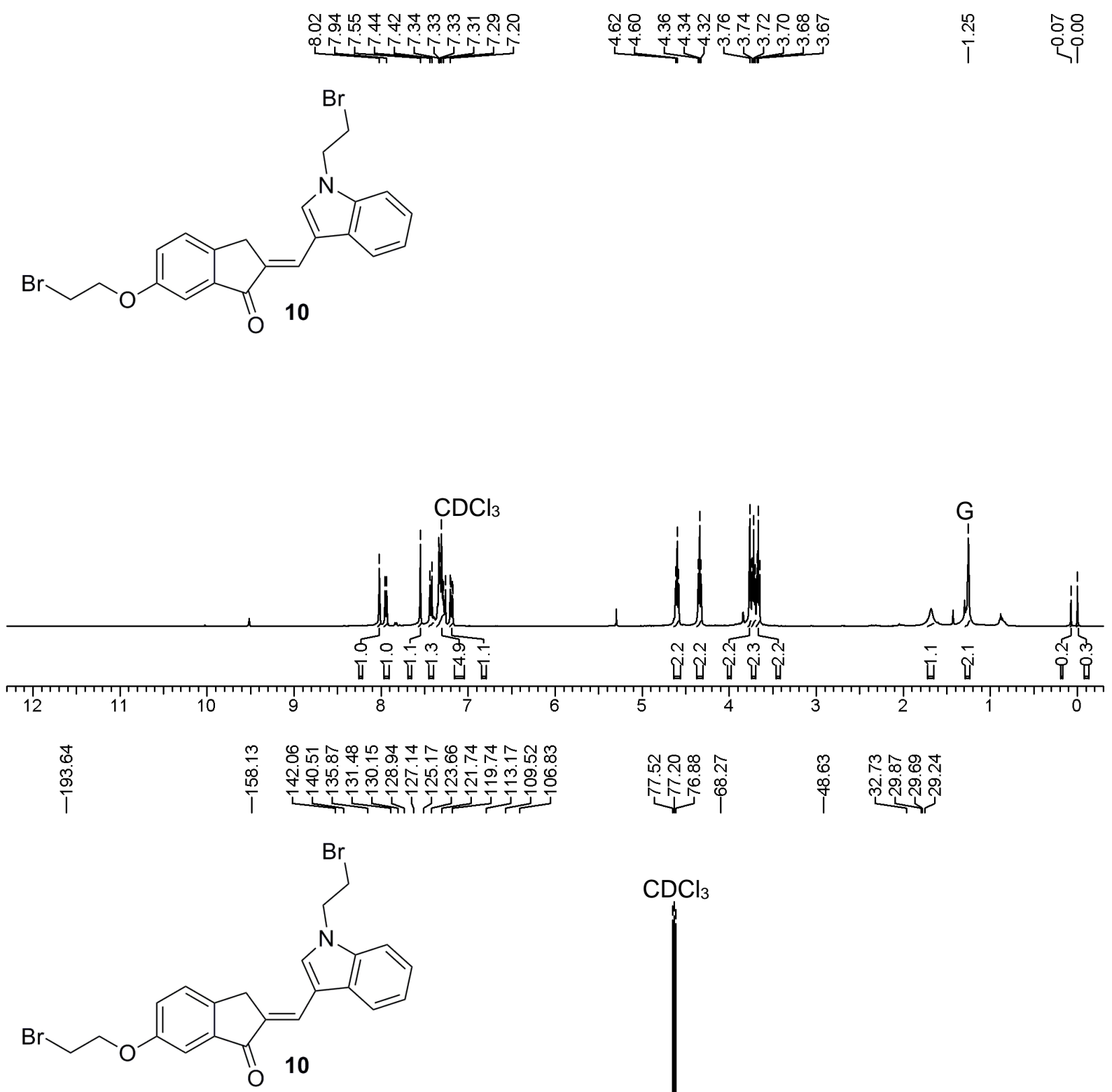

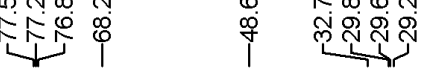

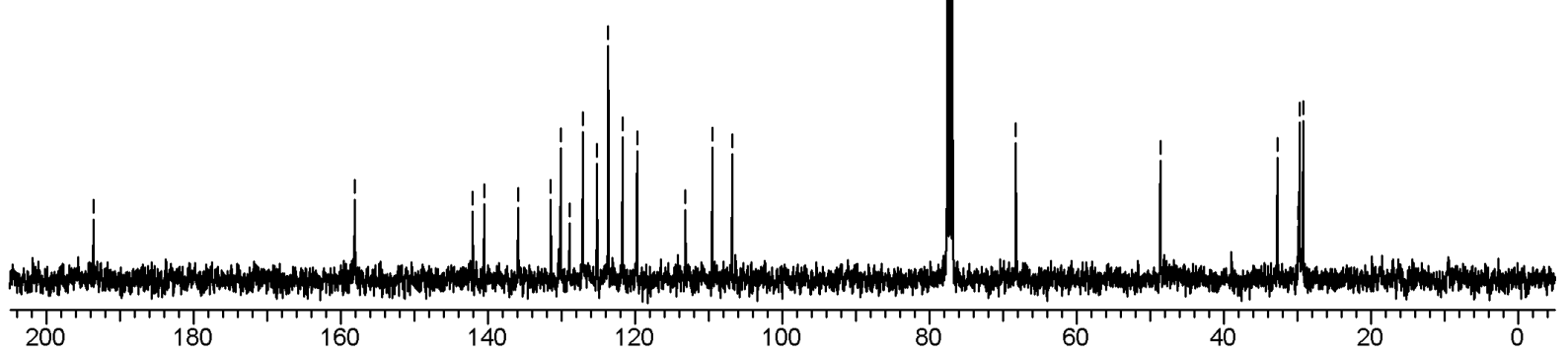


${ }^{1} \mathrm{H} \&{ }^{13} \mathrm{C}$ spectra of compound 11
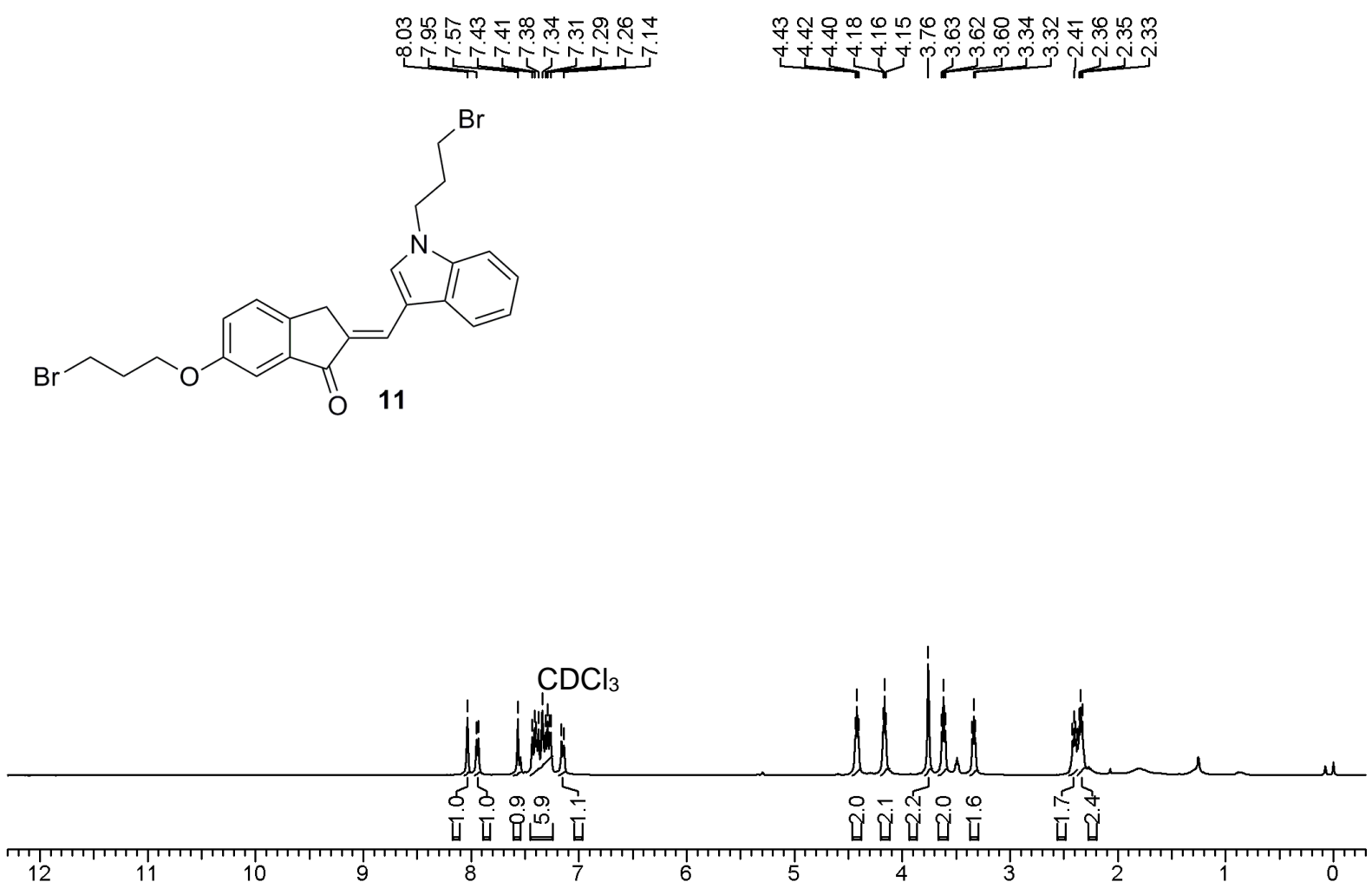<smiles>O=C1/C(=C/c2cn(CCCBr)c3ccccc23)Cc2ccc(OCCCBr)cc21</smiles>

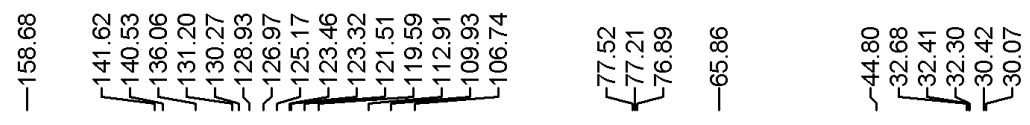<smiles>CC(C)C</smiles>
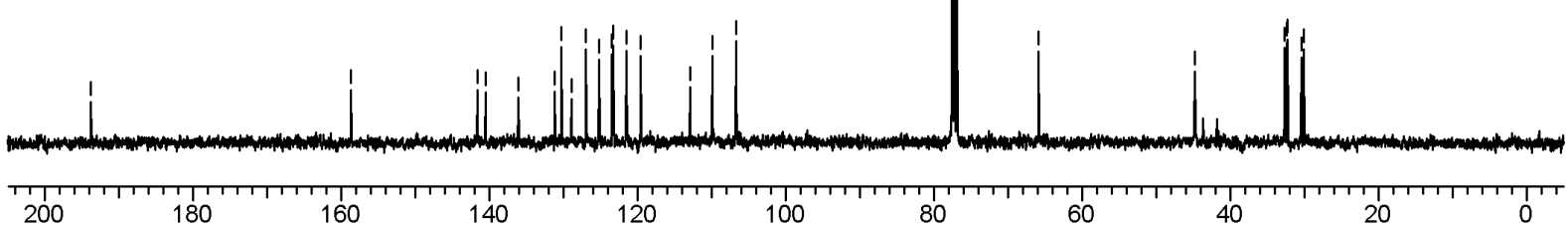
${ }^{1} \mathrm{H} \&{ }^{13} \mathrm{C}$ spectra of compound 12 (G - Grease)
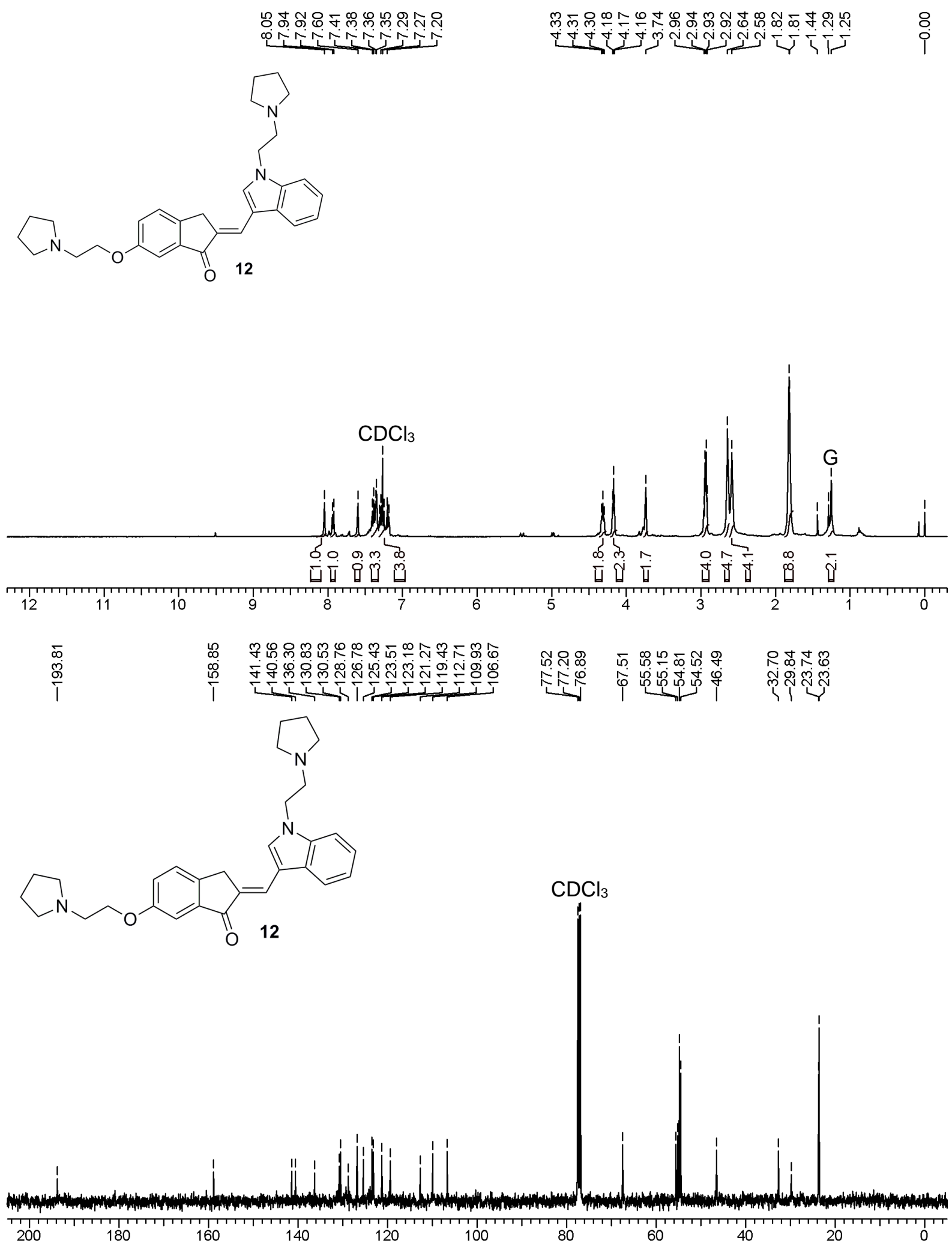


\section{${ }^{1} \mathrm{H} \&{ }^{13} \mathrm{C}$ spectra of compound 13}
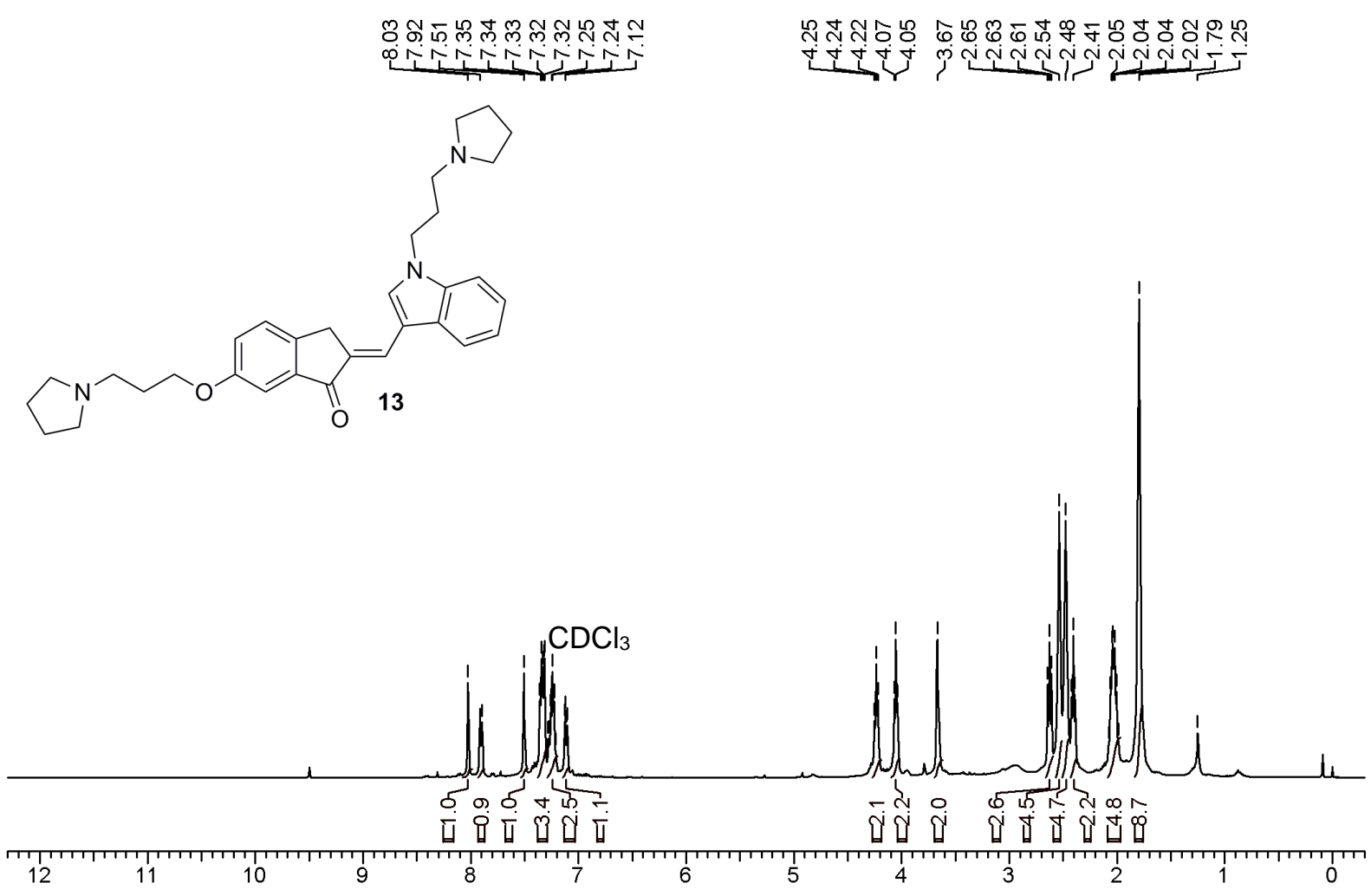

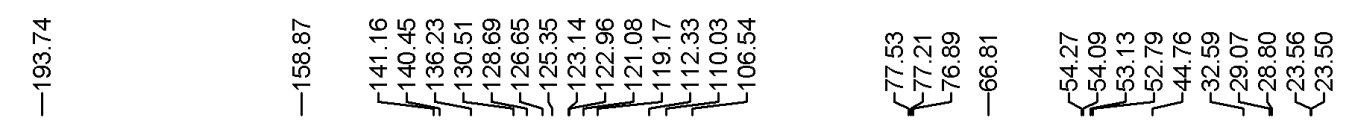

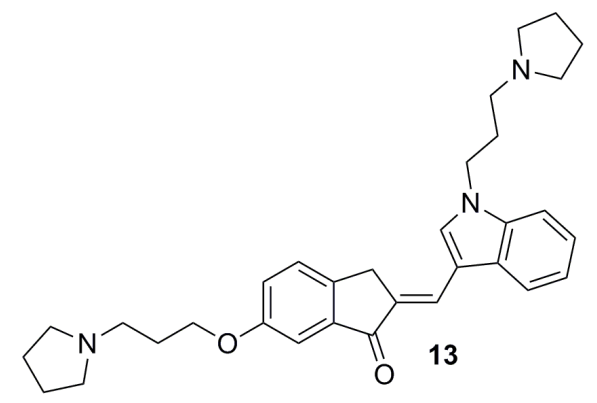

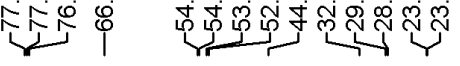

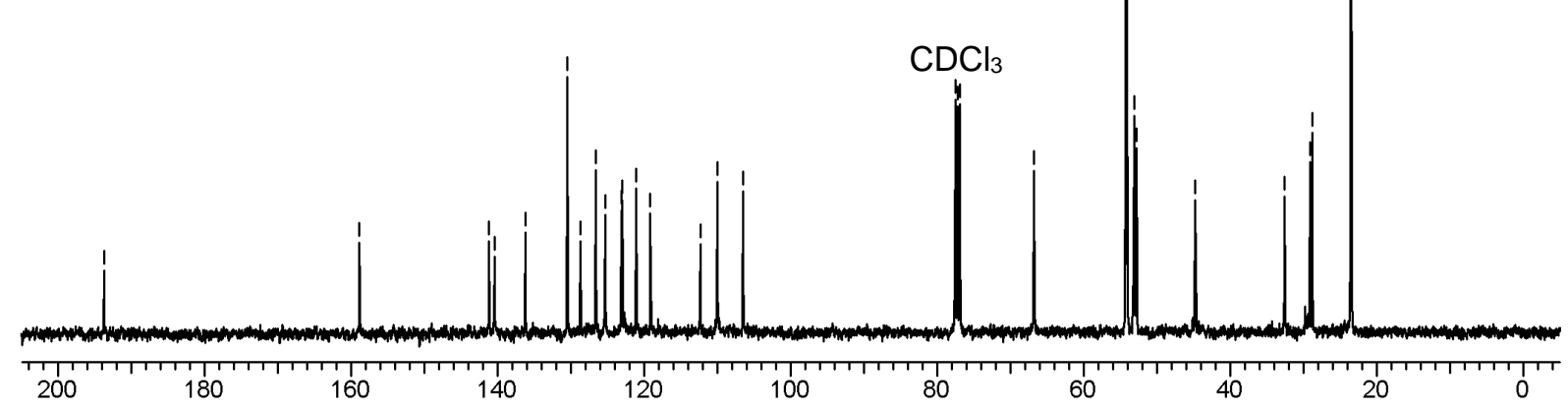




\section{${ }^{1} \mathrm{H} \&{ }^{13} \mathrm{C}$ spectra of compound InEt2}

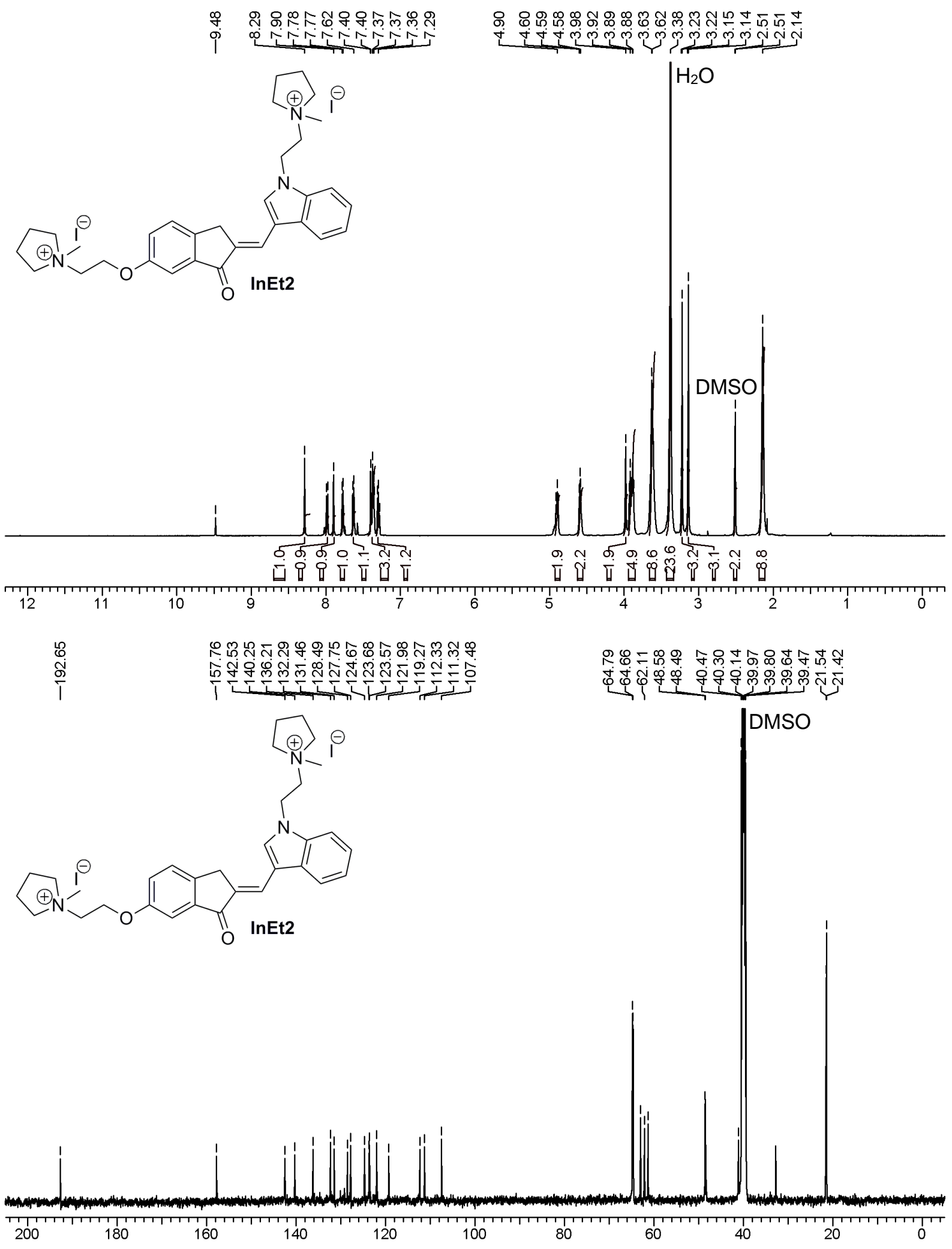




\section{${ }^{1} \mathrm{H} \&{ }^{13} \mathrm{C}$ spectra of compound InPr2}
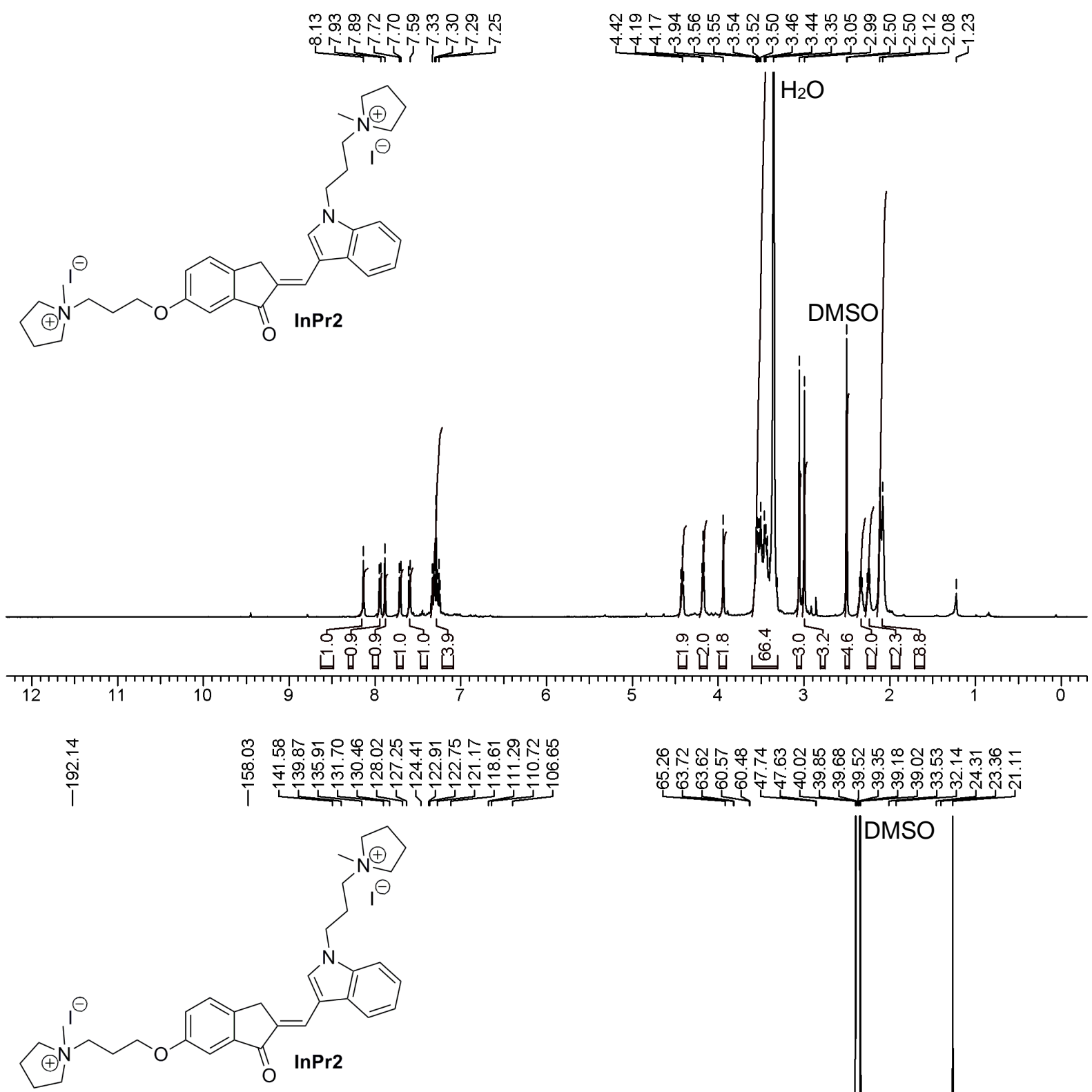

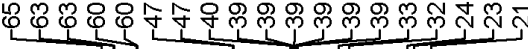

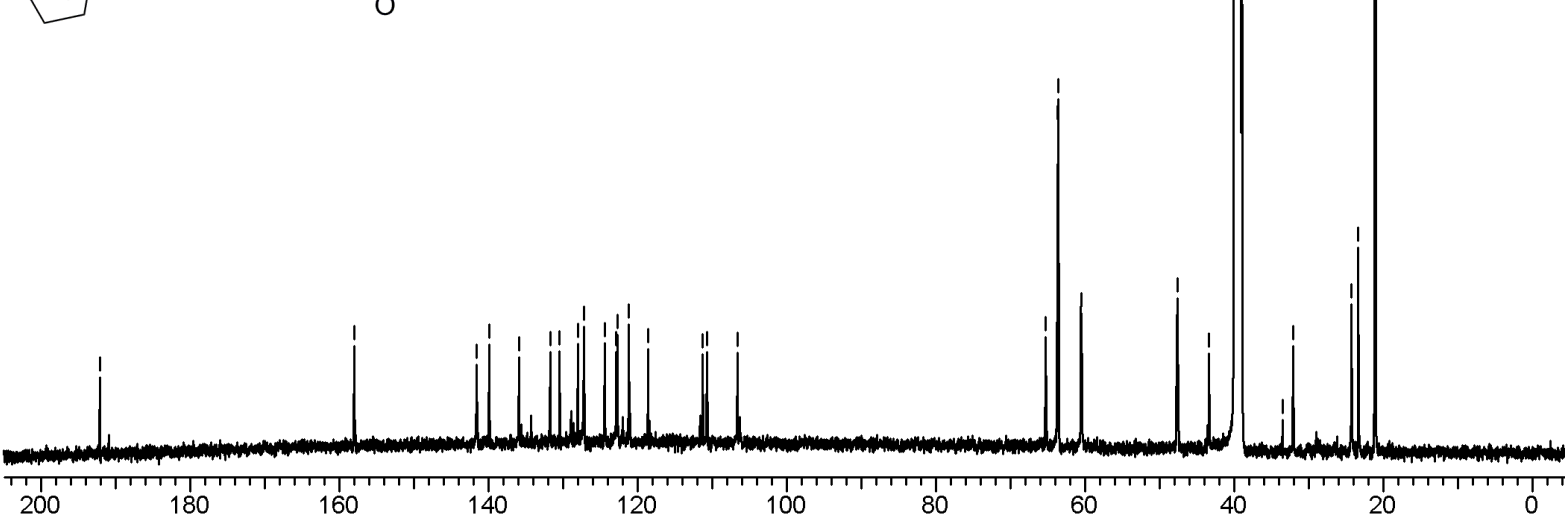

